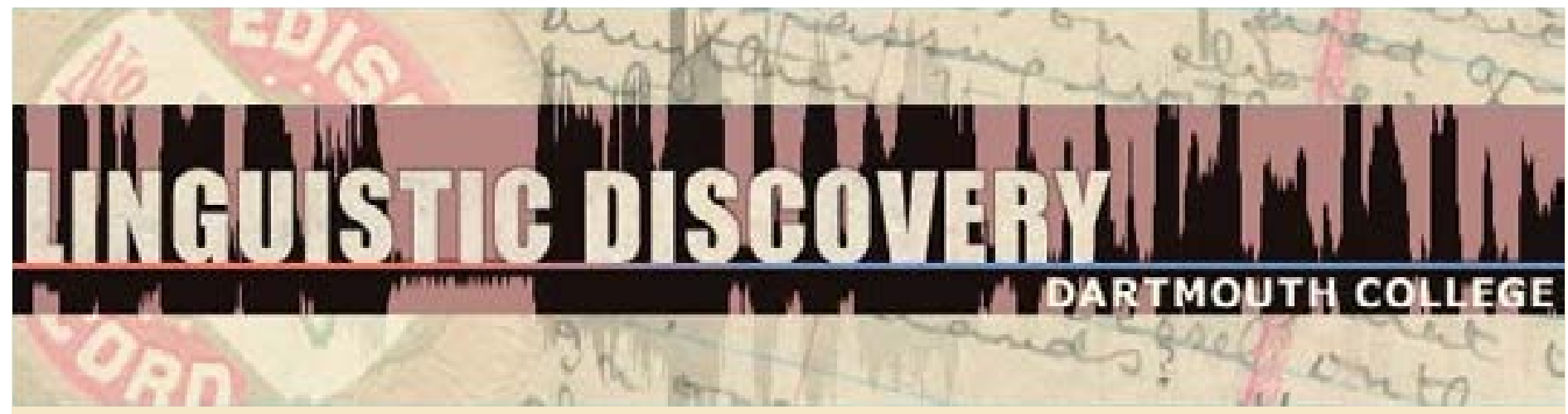

\begin{tabular}{|l|}
\hline Volume 9 \\
Issue 1 \\
2011 \\
\hline
\end{tabular}

\title{
The Phonetics and Phonology of Chuxnabán Mixe
}

Carmen Jany

California State University

doi: $10.1349 / P S 1.1537-0852 . A .388$

url: http://journals.dartmouth.edu/cgi-bin/WebObjects/ Journals.woa/1/xmlpage/1/article/388 


\section{The Phonetics and Phonology of Chuxnabán Mixe ${ }^{1}$ Carmen Jany}

This paper presents the first detailed description of the phonetic structures of the endangered Mexican indigenous language Chuxnabán Mixe, including a survey of the main features of the consonant system and acoustic measurements of the characteristics of the vowel system. Particular attention is given to phonological processes affecting the consonant system, such as voicing and place assimilation, and to the complex phonemic vowel distinctions between modal, breathy, glottalized, and interrupted vowels. While similar features have been identified in other Mixean and Mesoamerican languages, there are no acoustic studies. This work aims at introducing the phonetics and phonology of a previously undescribed language and at adding to the knowledge of Mixean and other Mesoamerican languages in general.

\section{Introduction}

Chuxnabán Mixe is a Mixe-Zoque language spoken by nine hundred people in one village in Oaxaca, Mexico. The Mixe territory is composed of two hundred and ninety communities (Torres Cisneros 1997). Each community speaks a different variety of Mixe, and some are mutually unintelligible. In many cases it is unclear whether a particular variety represents a distinct language or dialect, given that the documentation of Mixean languages is very limited. While some linguists divide Oaxaca Mixean into four main varieties: Lowland Mixe, Midland Mixe, South Highland Mixe, and North Highland Mixe (Campbell 1997; Wichmann 1995), the Ethnologue lists eight different Mixean languages spoken in Oaxaca and divided into two larger branches: Eastern Mixe with six languages and Western Mixe with two languages (Gordon 2005). Chuxnabán Mixe has been identified by its speakers as Midland Mixe, and corresponds to Quetzaltepec Mixe in the Ethnologue entry. To date, there are very few phonetic and phonological studies of Mixean languages (Bickford 1984, 1985; Crawford 1963; Dieterman 2008; Hoogshagen 1959; Jany 2006, 2007) and only a handful of grammatical descriptions (De la Grasserie 1898; Hoogshagen 1997; Ruiz de Bravo Ahuja 1980; Schoenhals 1982; Van Haitsma 1976).

While Chuxnabán Mixe continues to be learnt as a first language by children, the proficiency of these speakers is limited given that all education is offered in Spanish. Furthermore, the proficiency is rapidly declining because many people migrate to cities or to the United States. Communication with Mixean speakers from other villages often occurs in Spanish, especially if the variety spoken is very distinct. As a result, language use is restricted to unofficial daily activities within the community, and literacy is limited to the official language: Spanish. Due to the limited use, the growing bilingualism, and the exclusive literacy in the dominant language Chuxnabán Mixe is considered unsafe (Brenziger et al. 2003; Grenoble and Whaley (2006).

This paper presents the first detailed descriptive outline of the sounds and major phonological processes found in Chuxnabán Mixe. The data for this work comes from fieldwork conducted in 2006 and 2008 in the community, as well as from continuous sessions with a

\footnotetext{
${ }^{1}$ This work was in part supported by a Pilot Project Grant (PPG0044) from the Endangered Languages Documentation Programme (ELDP) of the Hans Rausing Endangered Languages Project at SOAS, University of London. The author also wishes to express gratitude to the Mixe community in Chuxnabán, in particular to the speakers who shared their knowledge and provided the data for this study.
} 
speaker living in the United States. Chuxnabán Mixe has a relatively simple consonant system and a complex vowel system with a phonemic vowel length distinction and a phonemic phonation contrast between plain, aspirated, and glottalized vowels. The vowel system varies greatly among the different Mixean languages and dialects (Crawford 1963; Hoogshagen 1997; Schoenhals 1982; Suslak 2003; Van Haitsma 1976; Wichmann 1995). The consonant system shows several traits common to Mesoamerica (Campbell et al. 1986), such as allophonic obstruent voicing and final sonorant devoicing, and it is identical across Mixean languages with some minor exceptions.

The following sections describe the consonant system, phonological processes affecting consonants, the complex vowel system, and orthographic conventions. The sound files included here were recorded between 2006 and 2008 during field trips to the village and with a speaker living in the United States. The recordings were made on either a Mini-Disc recorder or a Solid State Edirol recorder with a head-mounted Shure microphone and examined using Sound Forge and Praat software. Male and female speakers were recorded ranging from seventeen to eighty years of age, and data from elicitation, as well as from narratives, are included.

\section{The Consonant System}

There are eleven consonantal phonemes: four stops, two nasals, two fricatives, one affricate ${ }^{2}$, and two glides, in addition to eight phonemes /b, d, g, f, s, r, r, l/ occurring in Spanish loans. The consonants are summarized in Tables 1 and 2. Corresponding symbols in the practical orthography, if different from the symbols used in the International Phonetic Alphabet (IPA), are included in angled brackets. Phonemes from Spanish loans are in parentheses.

The glottal stop has only been identified as a phoneme when it forms part of a syllable nucleus, as in $\mathrm{V}^{2}$ and $\mathrm{V}^{2} \mathrm{~V}$ and in cases where a prefix is attached to a vowel-initial word. The glottal fricative $/ \mathrm{h} /$ functions as a phoneme in onset and coda position, as well as when it is part of the nucleus $\mathrm{VV}^{\mathrm{h}}$, with different phonetic realizations in each prosodic position.

\begin{tabular}{|c|c|c|c|c|c|c|}
\hline & Bilabial & Alveolar & Postalveolar & Palatal & Velar & Glottal \\
\hline Plosives & $\mathrm{p}$ & $\mathrm{t}$ & & & $\mathrm{k}$ & ${ }^{2}<’>$ \\
\hline Nasals & $\mathrm{m}$ & $\mathrm{n}$ & & & & \\
\hline Fricatives & & & $\int\langle x\rangle$ & & & $\mathrm{h}\langle\mathrm{j}\rangle$ \\
\hline Affricates & & ts & $\left(\mathrm{t} \int\langle\mathrm{ch}\rangle\right)^{3}$ & & & \\
\hline Glides & W & & & $\mathrm{j}\langle\mathrm{y}\rangle$ & & \\
\hline
\end{tabular}

\footnotetext{
${ }^{2}$ One of the affricates, <ch> /t $\mathrm{s}$, generally results from morpheme-induced palatalization, a suprasegmental phenomenon, and it is often not treated as a phoneme in descriptions of other Mixean languages. It has been included in the phoneme chart here for two reasons: (1) while morpheme-induced suprasegmental palatalization of other consonants manifests by having an onglide and an offglide, this is not always the case for <ch> and (2) in some instances it can not be traced back to morpheme-induced palatalization.

${ }^{3}$ íbid.
} 


\begin{tabular}{|c|c|c|c|c|c|c|}
\hline & Bilabial & Alveolar & Postalveolar & Palatal & Velar & Glottal \\
\hline Plosives & $\mathrm{p} /(\mathrm{b})$ & $\mathrm{t} /(\mathrm{d})$ & & & $\mathrm{k} /(\mathrm{g})$ & ${ }^{?}<>>$ \\
\hline Nasals & $\mathrm{m}$ & $\mathrm{n}$ & & & & \\
\hline Fricatives & (f) & (s) & $\int\langle x\rangle$ & & & $h\langle j\rangle$ \\
\hline Affricates & & ts & $\left(\mathrm{t} \int\langle\mathrm{ch}\rangle\right)$ & & & \\
\hline Rhotic & & $(\mathrm{r}) /(\mathrm{r})$ & & & & \\
\hline Lateral & & (1) & & & & \\
\hline Glides & $\mathrm{W}$ & & & $\mathrm{j}\langle\mathrm{y}\rangle$ & & \\
\hline
\end{tabular}

The following list of minimal pairs illustrates the phonemic contrasts.

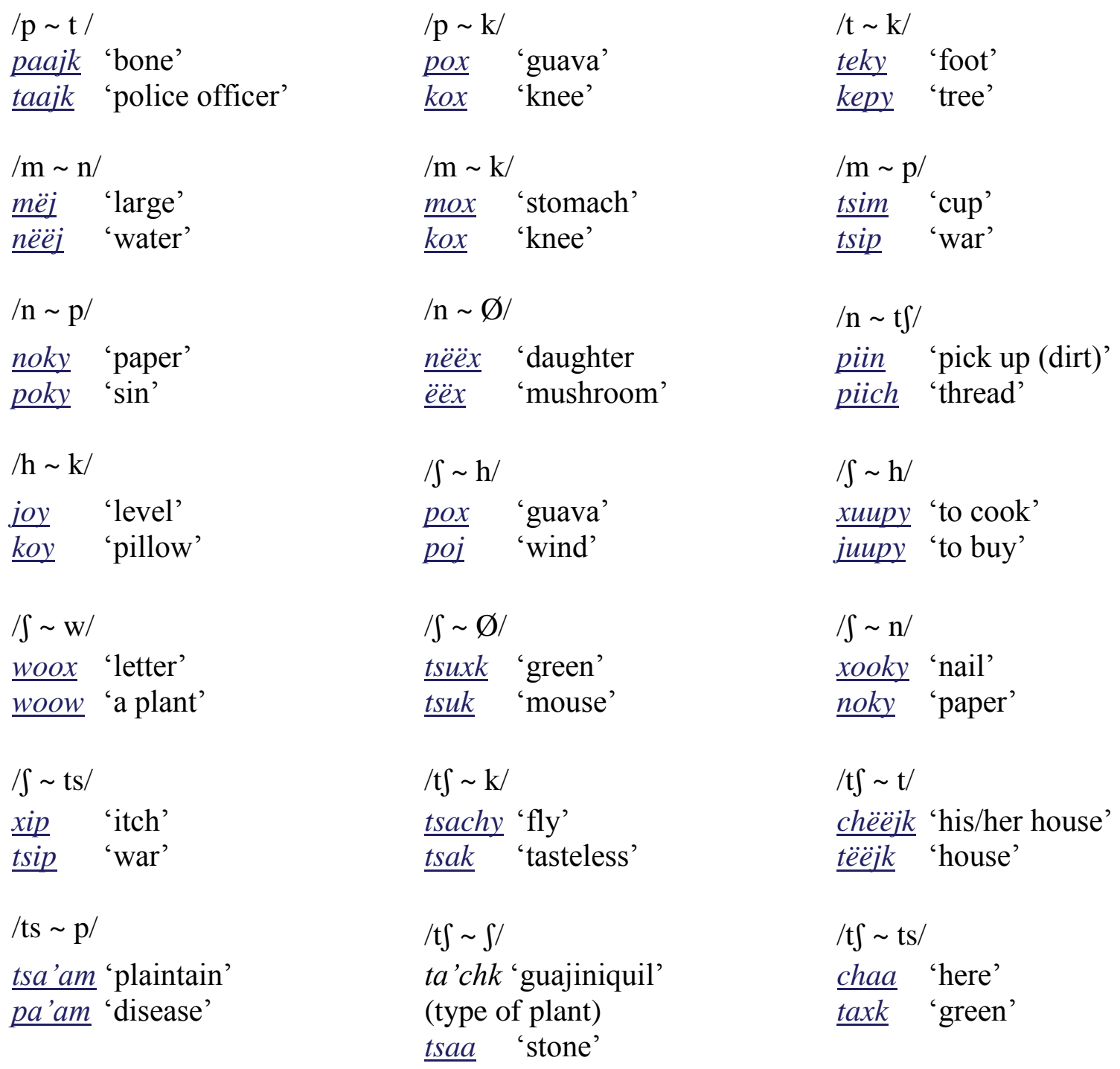



/w j/
/y $\sim \mathrm{h} /$
$/ \mathrm{j} \sim \mathrm{m} /$
$\frac{\text { kow }}{\text { koy }}$ 'guitar'
yo'kn 'neck'
yëk 'black'
jo'kn 'hook'

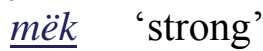

The glottal stop is inserted word-initially when a word starts with a vowel in order to avoid an onsetless syllable. This results in minimal pairs, such as 'ak 'skin' versus pak 'pigeon'. Given this predictable distribution, it is not regarded as showing a phonemic contrast in this position unless a prefix is attached, as in the following examples.
$\rho^{2} \sim \varnothing /$
$\rho^{2} \sim \varnothing /$

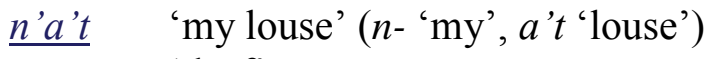
$\underline{m \text { 'ak }}$
'your skin' ( $m$ - your, $a k$ 'skin')
$\underline{\text { nat }}$ 'deaf'
mak 'large'

Glottal stops are always considered phonemic when they form part of the vowel nucleus as reflected in the laryngeal timing of creakiness in the middle or last portion of the vowel. The following minimal pairs illustrate this contrast.
$\rho^{2} \sim \varnothing /$
$/^{2} \sim \varnothing /$
$\underline{x u ' k x}$ 'tasty',
pu'uy 'panel, board'
xukx 'spin'
puиy 'seat'

The eight phonemes from Spanish loans /b, d, g, f, s, f, r, l/ are illustrated in the following examples. Minimal pairs are not presented here given that the phonemic contrasts refer to the Spanish language.

\begin{tabular}{|c|c|c|c|c|}
\hline$\underline{c e b u}$ & 'type of bull' & from Spanish & cebú & 'type of bull' \\
\hline$\overline{\text { cierrë }}$ & ‘zipper' & from Spanish & cierre & 'closure' \\
\hline suetrë & 'jacket' & from Spanish & suéter & 'jacket' (from English sweater) \\
\hline$\overline{\text { chancle }}$ & 'flip-flop' & from Spanish & chancla & 'flip-flop' \\
\hline$\overline{\text { cruts }}$ & 'cross' & from Spanish & cruz & 'cross' \\
\hline$\underline{b o t \ddot{e}}$ & 'boot' & from Spanish & bota & 'boot' \\
\hline$\overline{\text { lugar }}$ & 'place' & from Spanish & lugar & 'place' \\
\hline$\overline{\text { Dios }}$ & 'God' & from Spanish & Dios & 'God' \\
\hline$\overline{\text { nanuelë }}$ & 'grandmother' & from Spanish & abuela & 'grandmother' \\
\hline
\end{tabular}

Allophonic variations for all consonantal phonemes, except the ones from Spanish loans, and phonological processes affecting consonants are described in the following sections.

\subsection{Stops $p, t, k,{ }^{?}$}

Chuxnabán Mixe has four stops in bilabial, alveolar, velar, and glottal position. Their allophones include voiceless, voiced, aspirated, and unreleased stops; the glottal stop generally manifests as creakiness on the vowel. 


$$
\begin{array}{lll}
/ \mathrm{p} / & -> & {\left[\mathrm{p}, \mathrm{b}, \mathrm{p}^{\mathrm{h}}, \overrightarrow{\mathrm{p}}\right]} \\
/ \mathrm{t} / & -> & {\left[\mathrm{t}, \mathrm{d}, \mathrm{t}^{\mathrm{h}}, \overrightarrow{\mathrm{t}}\right]} \\
/ \mathrm{k} / & -> & {\left[\mathrm{k}, \mathrm{g}, \mathrm{k}^{\mathrm{h}}, \overrightarrow{\mathrm{k}}\right]} \\
/ \mathrm{P} / & -> & {\left[{ }^{\mathrm{P}}, \underset{\sim}{\mathrm{V}}\right]}
\end{array}
$$

The bilabial, alveolar, and velar stops /p, t, k/ are voiced after nasals and glides in word-initial and word-medial clusters, but not word-finally. Word-medial single consonants affected by palatalization are always voiced given that palatalization, a suprasegmental process in Mixean languages, creates an onglide in addition to an offglide. If the first consonant in a word-medial

\begin{tabular}{|c|c|c|c|}
\hline Voicing after nasals: & $\underline{n t e \dddot{e} j k}$ & 'my house' & $->\left[\mathrm{ndit}^{\mathrm{h}} \mathrm{k}\right]$ \\
\hline & $\underline{\text { wiintu'uk }}$ & 'one-eyed' & $->\left[{ }^{\prime} w i: n ' d u^{2} u k\right]$ \\
\hline Voicing after glides: & chowpech & 'expensive' & $->\left[\right.$ t $\int$ ow'bet $\left.^{\prime}\right]$ \\
\hline & puиуруaаjk & 'femur' & $\rightarrow$ [puij'bja: $\left.{ }^{\mathrm{h}} \mathrm{k}\right]$ \\
\hline & je'eykyëëxp & 's/he sent' & -> [he $\left.{ }^{2} \mathrm{ej}^{\prime} \mathrm{gjit}: \mathrm{sp}^{\urcorner}\right]$ \\
\hline Voicing intervocalically: & $\underline{a k a ' a n y}$ & 'it started' & $->\left[a^{\prime} a^{2} a n\right]$ \\
\hline & $\underline{\text { tёёрё }}$ & 'the one who' & $->\left[{ }^{\prime} \mathrm{t} \mathfrak{i}: b \dot{i}\right]$ \\
\hline No voicing after nasals finally: & $\underline{\text { maank }}$ & 'son’ & $->\left[\right.$ ma:nk $\left.k^{\mathrm{h}}\right]$ \\
\hline No voicing after aspiration: & $\underline{\text { naajkëmëch }}$ & 'we descend' & $->$ ['na: ${ }^{\mathrm{h}}$ kimit $\left.\int\right]$ \\
\hline No voicing after glottalization: & jyüüka’të & 'they lived' & $->\left[h j y: g^{\prime} a^{2} t i\right]$ \\
\hline $\begin{array}{l}\text { No voicing with palatalization } \\
\text { after voiceless consonant: }\end{array}$ & kachypyaajk & 'rib' & $\rightarrow\left[\right.$ kat $^{\prime}$ pja: $\left.^{\mathrm{h}} \mathrm{k}\right]$ \\
\hline
\end{tabular}
cluster is voiceless and palatalized, no voicing occurs, even though an offglide follows the cluster. The stops are also voiced intervocalically after plain and interrupted vowels, but not after aspirated or glottalized vowel nuclei. There is no voicing word-finally.

There is no voicing of intervocalic clusters containing stops and fricatives and geminates.

\begin{tabular}{|c|c|c|c|}
\hline Full form: & jëtu'un & 'thus' & $->\left[h i^{\prime} d u^{2} u n\right]$ \\
\hline Shortened form: & $\underline{t u ' u n}$ & 'thus' & $->\left[d^{2} u n\right]$ \\
\hline Full form: & mpomp & 'tomorrow' & $->\left[\mathrm{mbomp}^{\urcorner}\right]$ \\
\hline Shortened form: & pomp & 'tomorrow' & $->\left[\right.$ bomp $\left.^{\urcorner}\right]$ \\
\hline
\end{tabular}

$\begin{array}{llll}\text { No voicing of clusters: } & \underline{\text { tuktuujk }} & \text { 'eight' } & ->\left[\text { tuk }^{\mathrm{h} '} \mathrm{tu}^{\mathrm{h}}{ }^{\mathrm{h}} \mathrm{k}^{\mathrm{h}}\right] \\ & \underline{\text { taxtuujk}} & \text { 'nine' } & ->\left[\operatorname{tas}^{\prime} \mathrm{tu}^{\mathrm{h}} \mathrm{k}^{\mathrm{h}}\right] \\ \text { No voicing of geminates: } & \underline{\text { jappëk }} & \text { 'in, there' } & \left.\rightarrow \text { ['hap:ik }{ }^{\mathrm{h}}\right]\end{array}$

In some instances, word-initial syllables are dropped keeping the rest of the word with the original word-medial voiced stop. This results in word-initial voiced allophones. 
The voicing of stops is a common phenomenon in the world's languages (Ladefoged and Maddieson 1996). Allophonic alternations involving the voicing of stops after nasals and intervocalically are also reported for other Mesoamerican languages (Campbell et al. 1986) and for other Mixean languages (Crawford 1963; Dieterman 2008; Hoogshagen 1997; Schoenhals 1982; Van Haitsma 1976; Wichmann 1995). Hence, Chuxnabán Mixe is typical in this regard. Crawford (1963) notes for Totontepec Mixe that /t/ and / $/$ / are realized as voiced fricatives intervocalically; in Chuxnabán Mixe, they are realized as voiced stops.

The aspirated allophones $\left[\mathrm{p}^{\mathrm{h}}, \mathrm{t}^{\mathrm{h}}, \mathrm{k}^{\mathrm{h}}\right]$ generally occur word-finally in single stops, stopclusters, and other voiceless consonant clusters. Both stops tend to be aspirated in word-final consonant-clusters. In word-medial voiceless clusters, the first or both stops are occasionally aspirated. The aspirated allophones are also found in clusters with alveolar and post-alveolar fricatives and affricates, such as $k x p, p x p$, tsp, xp, $k x k, p x k$, $t s k$, and $x k$. Occasionally, initial stops are aspirated. Some speaker variation is noted, as well as variation within multiple instances of the same word and speaker. Similar variations have been reported for other Mixean languages, such as Isthmus Mixe, also known as Guichicovi Mixe, where aspiration is described as a stylistic variation (Dieterman 2008).

\begin{tabular}{|c|c|c|c|}
\hline \multirow[t]{3}{*}{ Aspirated stops word-finally: } & $\underline{\text { määjtsk }}$ & 'two' & $->\left[\mathrm{mæ}^{\mathrm{h}}{ }^{\mathrm{tsk}}{ }^{\mathrm{h}}\right]$ \\
\hline & jot & 'stomach' & $->\left[\operatorname{hot}^{\mathrm{h}}\right]$ \\
\hline & piyë'kp & 'to run' & $->\left[p^{1} j \dot{j i}^{?} k^{h} p^{h}\right]$ \\
\hline \multirow[t]{2}{*}{ Aspirated stops word-medially: } & puujtpë & 'grasshopper' & $->\left[{ }^{\prime} p u_{:}{ }^{h} t^{h} p^{h} \dot{\mathfrak{t}}\right]$ \\
\hline & woknëëj & 'stream' & $->$ [wok ${ }^{\mathrm{hl}}$ ni:h] \\
\hline \multirow[t]{2}{*}{ Aspirated stops word-initially: } & $\underline{\text { tutk }}$ & 'turkey' & $->\left[\mathrm{t}^{\mathrm{h}} \mathrm{ut}^{\mathrm{h}} \mathrm{k}^{\mathrm{h}}\right]$ \\
\hline & $\underline{\text { kow }}$ & 'guitar' & $->\left[\mathrm{k}^{\mathrm{h}} \mathrm{ow}\right]$ \\
\hline Aspirated stops in clusters: & $\underline{\text { kaapxp }}$ & 'to talk' & $->\left[\right.$ ka:psp $\left.{ }^{h}\right]$ \\
\hline
\end{tabular}

The occasional word-initial aspiration of voiceless stops is confirmed by measurements of voice onset time (VOT) ranging from 5-123 ms. A total of 99 tokens were measured from four different speakers, two females and two males. The data included 6-12 tokens per voiceless stop in 2-4 different monosyllabic words with the target consonants in word-initial position, mostly before $/ \mathrm{a} /$ and before $/ \mathrm{i} /$ or $/ \mathrm{u} /{ }^{4}$. The number of tokens is summarized in Figure 1 . Figure 2 illustrates the mean VOT values for each stop by speaker.

\begin{tabular}{|l|l|l|l|l|l|l|}
\hline & & F1 & F2 & M1 & M2 & Total \\
\hline & $\mathbf{k}$ & 9 & 9 & 6 & 6 & 30 \\
\hline & $\mathbf{p}$ & 12 & 12 & 12 & 9 & 45 \\
\hline & $\mathbf{t}$ & 6 & 6 & 6 & 6 & 24 \\
\hline Total & & 27 & 27 & 24 & 21 & 99 \\
\hline
\end{tabular}

Figure 1: Number of tokens for VOT measurements. $\mathrm{F}=$ female; $\mathrm{M}=$ male.

\footnotetext{
${ }^{4}$ The words used for the measurements were pak 'pigeon', pax 'deer', pich 'tortilla dough', pik 'round', taajk 'village police', taak 'mother', tun 'mountain, line', $\underline{\text { tux }}$ 'yellow fruit', kat 'toucan', kachy 'basket', kow 'guitar', kuuy 'rabbit', and kum 'sweet fruit'.
} 


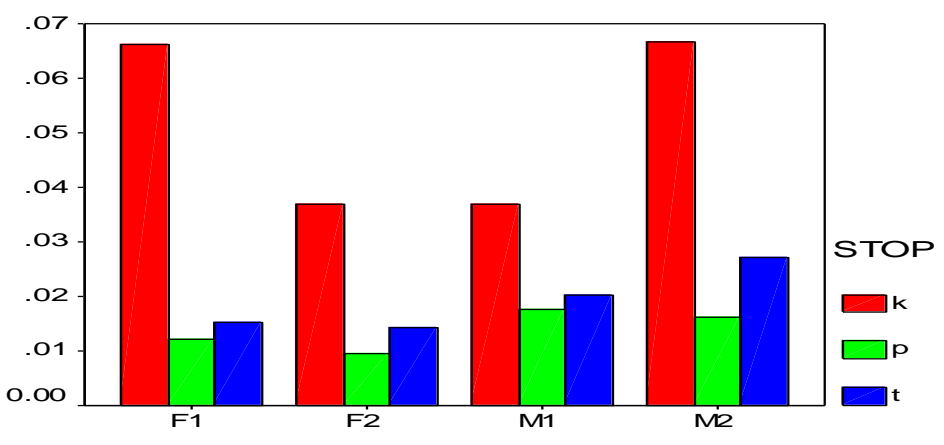

SPEAKER

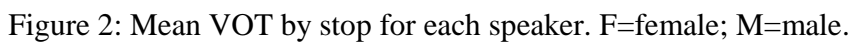

The results in Figure 2 reveal great speaker variation with respect to VOT, especially for the velar voiceless stop $/ \mathrm{k} /$. In fact, the measurements indicate a VOT range from $22-123 \mathrm{~ms}$ for $/ \mathrm{k} /$ (this is not obvious in Figure 2, which displays only the mean values). $/ \mathrm{p} /$ and $/ \mathrm{t} /$ show less variation with VOT for $/ \mathrm{p} /$ ranging from 6-26 $\mathrm{ms}$ and for $/ \mathrm{t} /$ from 5-37 ms. When comparing the three places of articulation, it is apparent that VOT is significantly longer for velars than for bilabials and alveolars and that it increases with backness.

In addition to VOT, closure duration was measured for the three voiceless stops. Monosyllabic words were used where consonants followed a low vowel /a/ or /ä/ and a high vowel /i/ or / $\mathrm{u} /$. The data consisted of 3-9 tokens per stop in 1-3 different words with the target consonants word-finally ${ }^{5}$. The number of tokens is summarized in Figure 3. The mean values for the duration measurements are illustrated in Figure 4.

\begin{tabular}{|l|l|l|l|l|l|l|}
\hline & & F1 & F2 & M1 & M2 & Total \\
\hline & $\mathbf{k}$ & 6 & 9 & 9 & 6 & 30 \\
\hline & $\mathbf{p}$ & 9 & 3 & 3 & 6 & 20 \\
\hline & $\mathbf{t}$ & 9 & 9 & 9 & 9 & 36 \\
\hline Total & & 24 & 20 & 21 & 21 & 86 \\
\hline
\end{tabular}

Figure 3: Number of tokens for closure duration by stop for each speaker. F=female; $M=$ male.

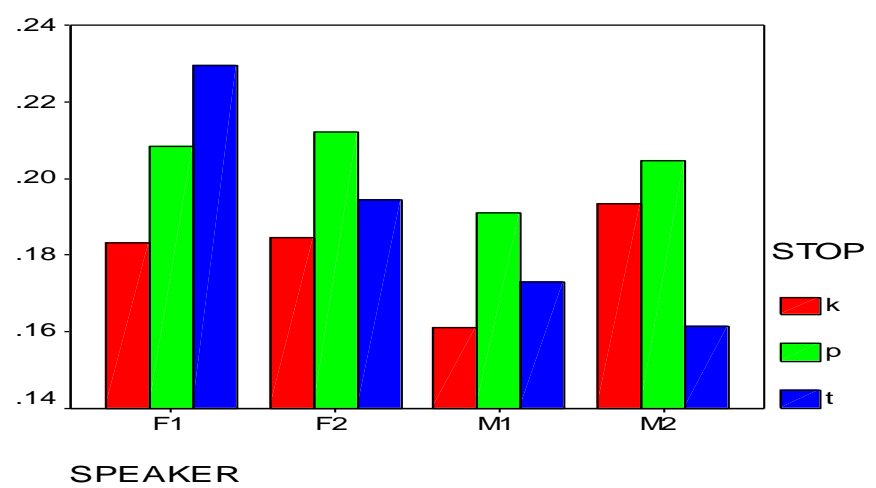

Figure 4: Mean closure duration by stop for each speaker. $F=$ female; $M=$ male.

\footnotetext{
${ }^{5}$ The words used for the measurements were täp 'you have', $\underline{t s i p}$ 'war', $\underline{\text { tsaajp }}$ 'sky', $\underline{\text { kat }}$ 'toucan', $\underline{\text { nat }}$ 'deaf', $\underline{j u t}$ 'hole', pak 'pigeon', pik 'round'.
} 
In general, closure duration decreases with backness, though the mean closure duration for each stop varies greatly by speaker and token. The numbers range from 174-250 ms for /p/, 108-284 $\mathrm{ms}$ for $/ \mathrm{t} /$, and 120-254 $\mathrm{ms}$ for $/ \mathrm{k} /$. This variation in closure duration could be interpreted as a phonetic correlate of a possible fortis/lenis contrast (Bickford 1985) with fortis stops showing a greater duration than lenis stops word-finally. It would then be expected that stops in the same word would always be either fortis or lenis across speakers having roughly the same duration. However, this is not the case as Figure 5 illustrates for $/ \mathrm{t} /$ in jut 'hole' and / $\mathrm{k} /$ in pik 'round'.

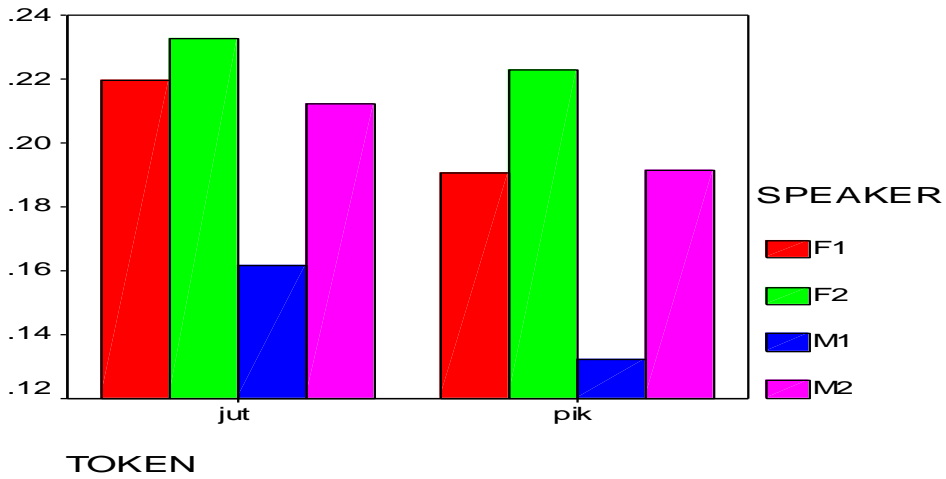

Figure 5: Mean closure duration for $/ \mathrm{t} /$ and $/ \mathrm{k} /$ in $\underline{j u t}$ and pik. $\mathrm{F}=$ female; $\mathrm{M}=$ male.

The results for VOT and closure duration are consistent with the well-documented relation across languages between VOT, closure duration, and place of articulation whereby VOT is shorter for bilabials than for velars, and alveolars have an intermediate value between the two (Maddieson 1997; Cho and Ladefoged 1999). Moreover, there is often an inverse correlation between closure duration and VOT whereby bilabial closures are longer than velars, again with alveolars showing an intermediate value between the two (Maddieson 1997; Cho and Ladefoged 1999).

The voiceless stops are occasionally unreleased when occurring in consonant clusters. The same words have been recorded with released and unreleased allophones for the same speakers, hence no conditioning factor can be identified. Nevertheless, the voiceless bilabial stop /p/ is most often unreleased word-finally when following a bilabial nasal $/ \mathrm{m} /$. The waveforms in Figures 6 and 7 illustrate the point.

\begin{tabular}{|c|c|c|c|}
\hline \multirow[t]{5}{*}{ Unreleased voiceless stops: } & jaamp & 'gray' & -> [ha:mp $]$ \\
\hline & pomp & 'tomorrow' & $->[$ bomp $\urcorner]$ \\
\hline & je'eykyёёхр & 's/he sent' & -> [he ${ }^{2} \mathrm{ej}^{\prime}$ gjitspp $]$ \\
\hline & maajktëkëëk & 'thirteen' & $->\left[\mathrm{ma}^{\mathrm{h}} \mathrm{k}^{\urcorner} \mathrm{tit}^{\prime} \mathrm{git} \mathrm{k}\right]$ \\
\hline & $\underline{\text { tkay }}$ & 'he ate' & $->\left[\mathrm{t}^{\urcorner} \mathrm{kaj}\right]$ \\
\hline
\end{tabular}




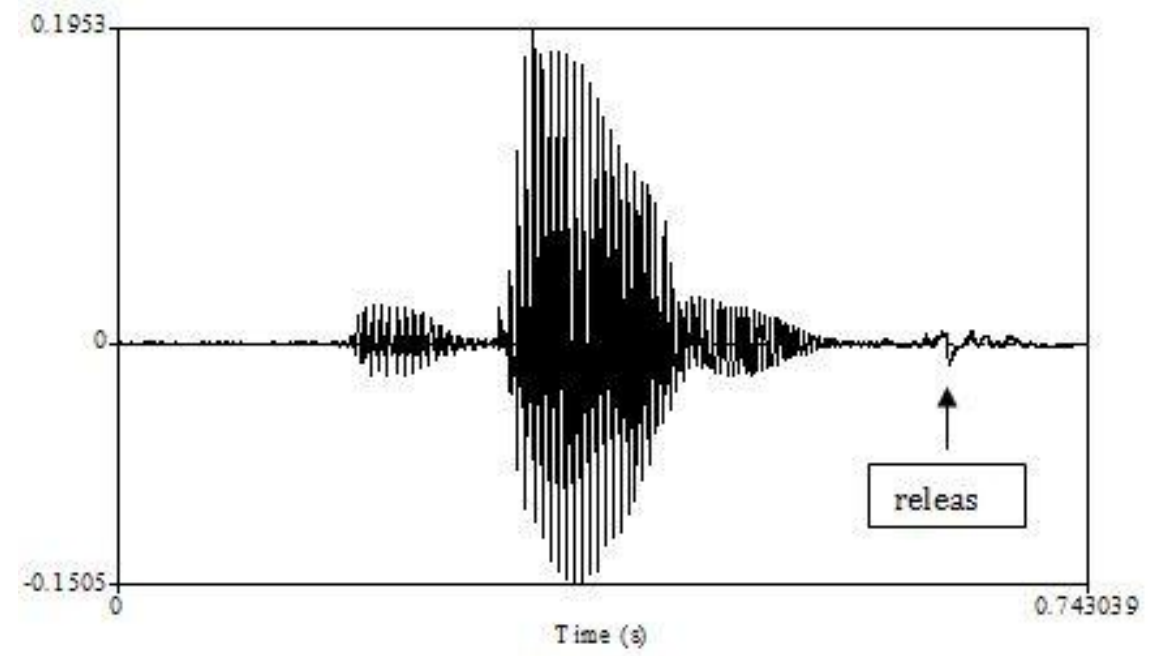

Figure 6: Released final stop /p/ in pomp 'tomorrow' (same speaker as Figure 7)

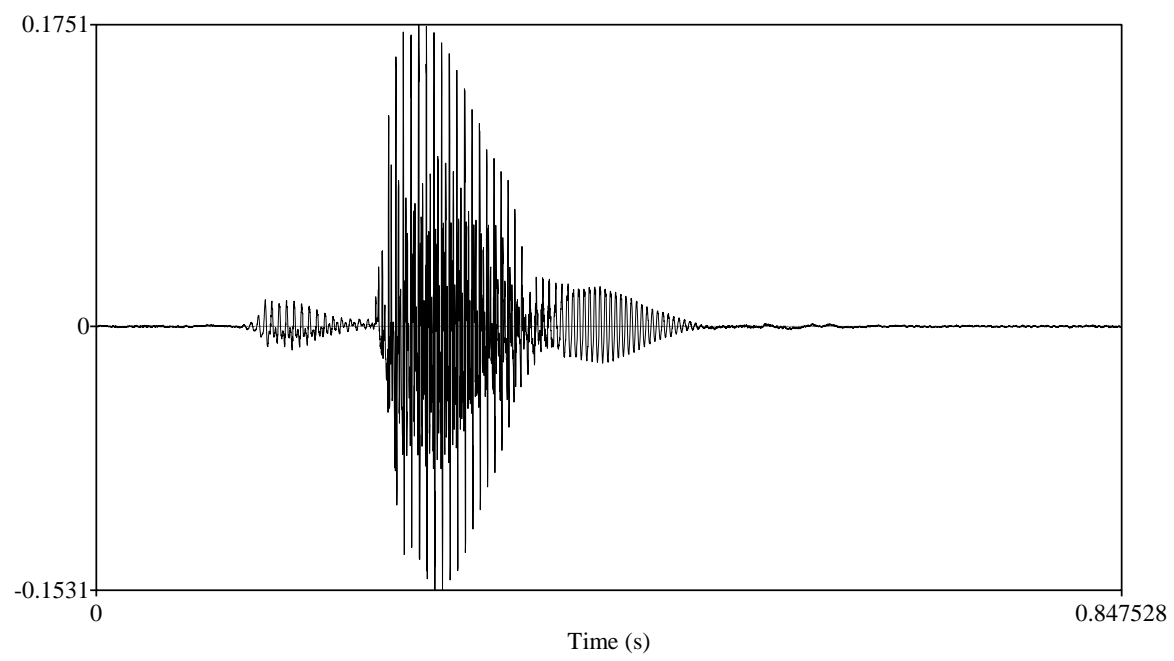

Figure 7: Unreleased final stop /p/ in pomp 'tomorrow' (same speaker as Figure 6)

Unreleased stops have also been described for other Mixean varieties (Crawford 1984; Dieterman 2008) in similar environments as observed in Chuxnabán Mixe. Dieterman (2008) indicates that stops are unreleased before pauses in Isthmus Mixe. Crawford (1984) states for Totontepec Mixe that $p, t, k$ are unreleased word-finally and before other consonants. An unreleased bilabial stop has also been reported for Oaxaca Chontal, another Mesoamerican language spoken in Oaxaca (Maddieson et al. 2009).

The glottal stop generally manifests as creakiness on the surrounding vowels within the same word. It occurs word-initially and word-medially in intervocalic position. Word-initial glottal stops are generally inserted to avoid onsetless syllables, but this is not a general rule as there are instances with no initial glottal stops if there are no prefixes. The glottal stop always surfaces when a prefix is attached to a vowel-initial root. The glottal stop of the glottalized and interrupted vowel nuclei is discussed in section 3 . 


\begin{tabular}{|c|c|c|c|}
\hline \multirow[t]{2}{*}{ Glottal stop as creaky vowels: } & $\underline{\text { aajch }}$ & 'brother' & $>\left[\underset{\sim}{a}{ }^{h} \mathrm{t} \int\right]$ \\
\hline & $\underline{e e x}$ & 'crab' & $>[\underset{\sim}{\mathrm{e}} \mathrm{s}]$ \\
\hline \multirow[t]{3}{*}{ Vowel-initial root with prefix: } & $\underline{i i x}$ & 'see' & $>$ [i:s] or [i:s] \\
\hline & $\underline{t^{\prime} i i x}$ & 's/he saw' & $>$ [ti:s $]$ \\
\hline & yaa'iix & 'you can see it' & $>$ [ja: ij:s] \\
\hline
\end{tabular}

\subsection{Fricatives $\int$, $h$}

There are two fricatives in Chuxnabán Mixe in postalveolar and glottal position: $/ \int, \mathrm{h} / \mathrm{.}$ The postalveolar fricative has four allophones, a retroflexed and nonretroflexed voiceless and voiced sibilant. The glottal fricative phoneme has only two allophones in onset and coda position, voiceless and voiced, and differs from the aspiration found in syllable nuclei (see section 3).

$\begin{array}{lll}/ \mathrm{J} / & \rightarrow & {[\mathrm{S}, \mathrm{s}, \mathrm{3}, \mathrm{z}]} \\ / \mathrm{h} / & \rightarrow & {[\mathrm{h}, \mathrm{h}]}\end{array}$

The postalveolar fricative is retroflexed unless palatalization occurs. Voicing occurs after nasals and glides word-initially and word-medially, but not word-finally. Voicing also occurs when the fricative is affected by palatalization in word-medial position, given the onglide created by palatalization, and before glides. It is also voiced intervocalically after plain and interrupted vowels. Occasionally, only partial voicing occurs in the initial segment, as shown in Figure 8. There is no voicing word-finally. The glottal fricative is voiced intervocalically, as in Figure 9.

\begin{tabular}{|c|c|c|c|}
\hline \multirow{3}{*}{$\begin{array}{l}\text { Retroflexed voiceless } \\
\text { postalveolar: }\end{array}$} & $\underline{\operatorname{taxk}}$ & 'four' & $->$ [ta:sk] \\
\hline & $\underline{x u k x}$ & 'hummingbird' & -> [sukș] \\
\hline & $\underline{x a x}$ & 'charales' & $->$ [şas] (type of fish) \\
\hline \multirow{3}{*}{$\begin{array}{l}\text { Retroflexed voiced } \\
\text { postalveolar: }\end{array}$} & $\underline{\operatorname{axux}}$ & garlic' & $->$ [a'zus] \\
\hline & puиxiix & 'mushroom part' & -> [pu:'zi:s] \\
\hline & timxëëwj & 'what's your name?' & -> [tim'zit:wh] \\
\hline $\begin{array}{l}\text { Nonretroflexed voiceless } \\
\text { postalveolar: }\end{array}$ & xyiits & 'heart' & $->\left[\int j i \mathrm{i} t \mathrm{~s}\right]$ \\
\hline $\begin{array}{l}\text { Nonretroflexed voiced } \\
\text { postalveolar: }\end{array}$ & naaxyuujk & 'worm' & $->$ [na:3'ju: $\left.{ }^{\mathrm{h}} \mathrm{k}\right]$ \\
\hline \multirow[t]{2}{*}{ Voiceless glottal: } & jot & 'stomach' & $->[$ hot $]$ \\
\hline & $\underline{m \ddot{e} j}$ & 'large’ & $\rightarrow[\mathrm{mih}]$ \\
\hline \multirow[t]{2}{*}{ Voiced glottal: } & tsujoch & 'in the dream' & $\rightarrow$ [tsu'fots] \\
\hline & ројёпё & 'fast' & -> ['pohinini] \\
\hline
\end{tabular}




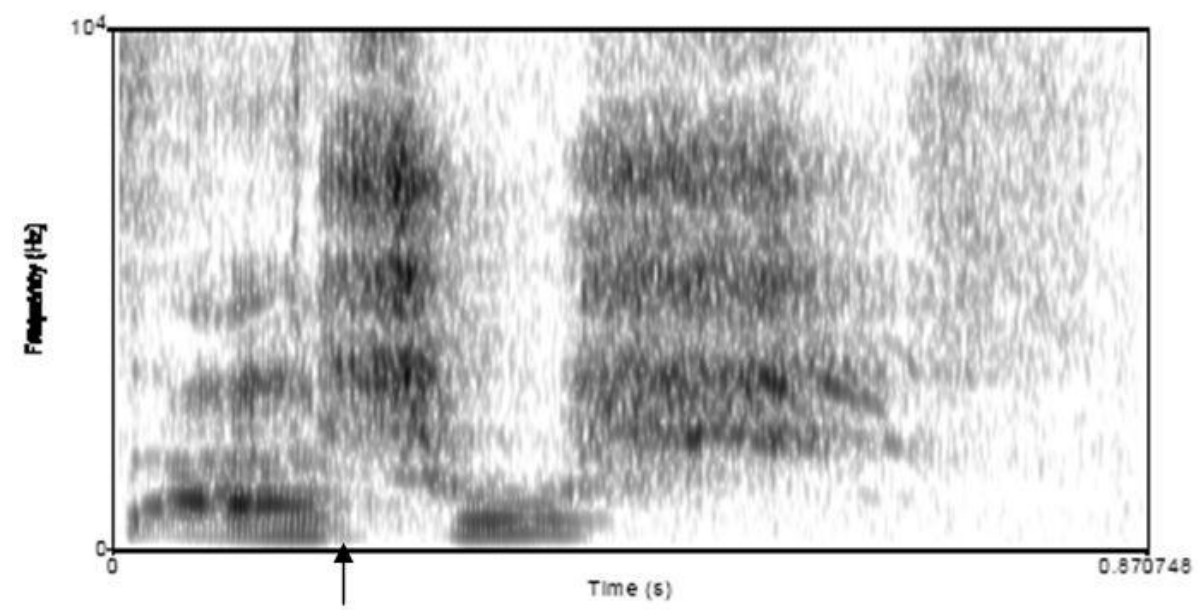

Figure 8: Only partial voicing of the first fricative $/ \int /$ in $\underline{\text { axux }}$ 'garlic'

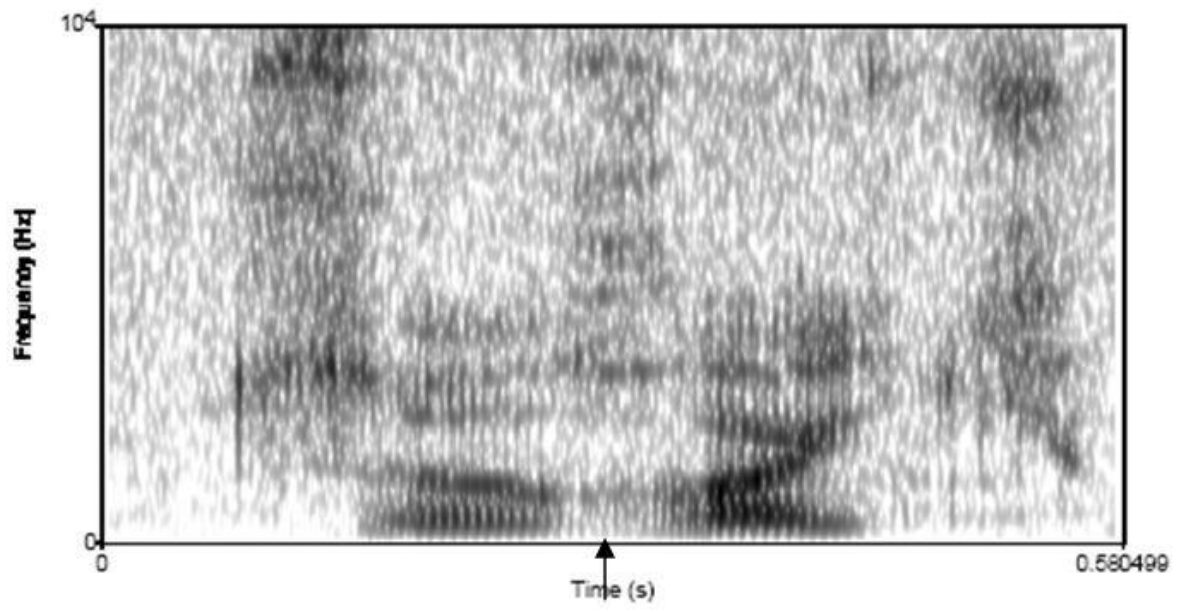

Figure 9: Voicing of the fricative /h/ in tsujoch 'in the dream'

Fricative voicing has also been reported for other Mixean languages. Dieterman (2008) notices intervocalic voicing of $/ \mathrm{h} /$ in the related Isthmus Mixe. She indicates that voiceless [h] shows more friction than voiced [h]. Fricative voicing is not a common phenomenon in the world's languages (Ladefoged and Maddieson 1996:176-8). Hence, Mixean languages are typologically special in this regard.

Duration measurements of four speakers, two males and two females, reveal that word-final fricatives are longer than those in word-initial position and that those affected by palatalization are longer than those not affected by it in the same position. Final lengthening is typologically common and has been reported in a number of languages (Gordon 2006; Hayes 1989). A total of 120 tokens were measured, 3 repetitions of 10 different monosyllabic words for each speaker. They include / $/$ / word-initially, word-finally, and palatalized word-finally ${ }^{6}$. Only voiceless allophones were measured. The results in Figures 10 and 11 illustrate final lengthening and lengthening as a result of palatalization respectively.

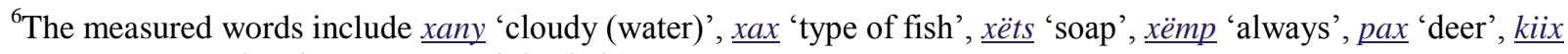

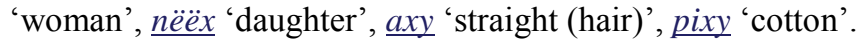




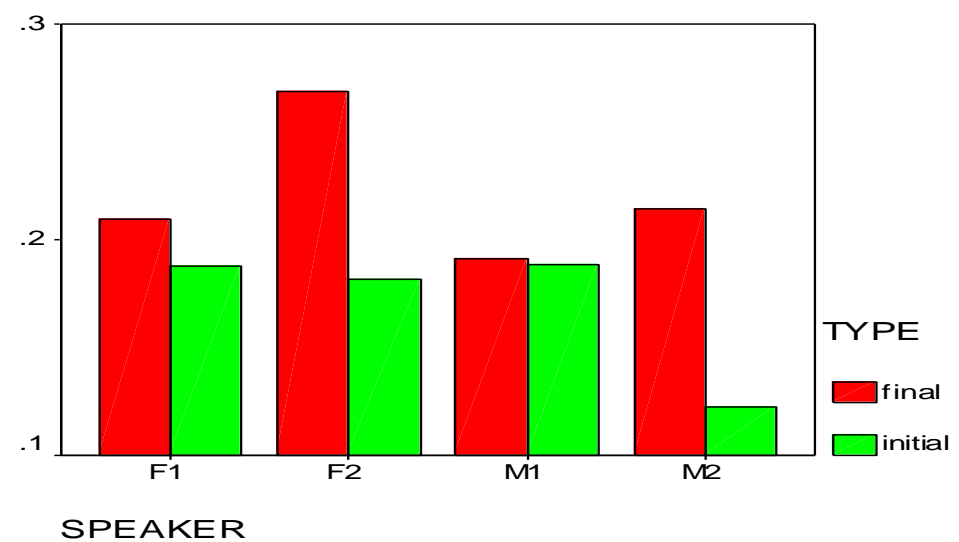

Figure 10: Duration of / $/$ / word-initially vs. word-finally. F=female; $M=$ male

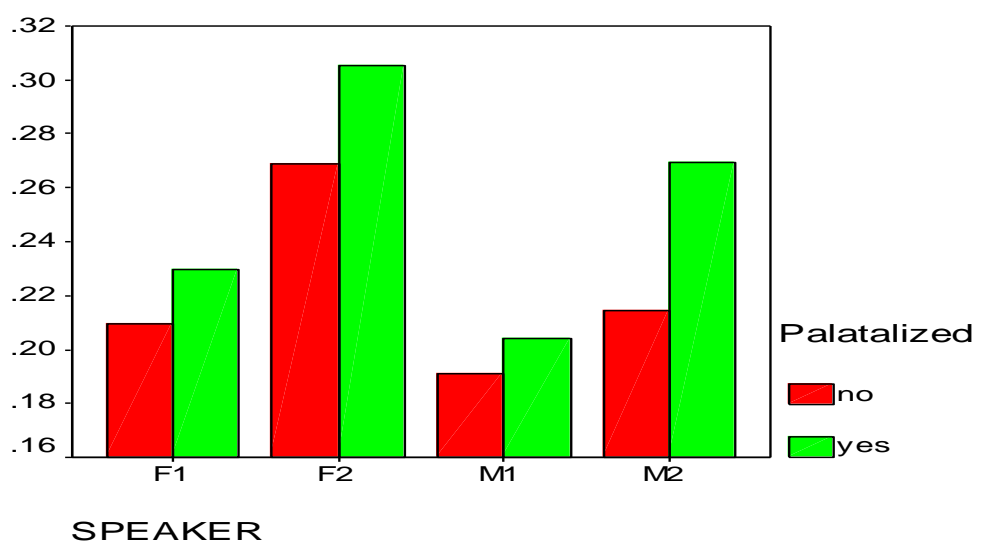

Figure 11: Duration of final / $/ /$ with and without palatalization. $F=$ female; $M=$ male

The glottal fricative has two allophones [h, h] when functioning as an onset or as a coda. Its phonetic realization is clearly different from the aspiration found in breathy vowels. The turbulence in airflow is stronger if $/ \mathrm{h} /$ belongs to the onset or coda, and it is longer in duration. Furthermore, in syllables where $/ \mathrm{h} /$ functions as a coda, the preceding vowel does not exhibit a steady decay in intensity as in aspirated nuclei. This is shown in Figures 12 and 13.

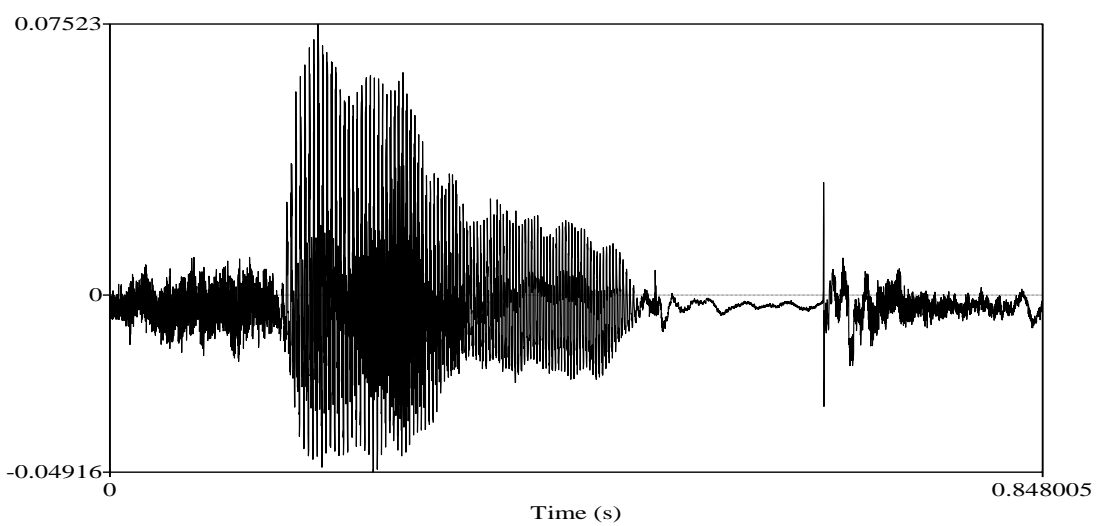

Figure 12: /h/ as onset and aspirated vowel in „ёёip 'nose' 


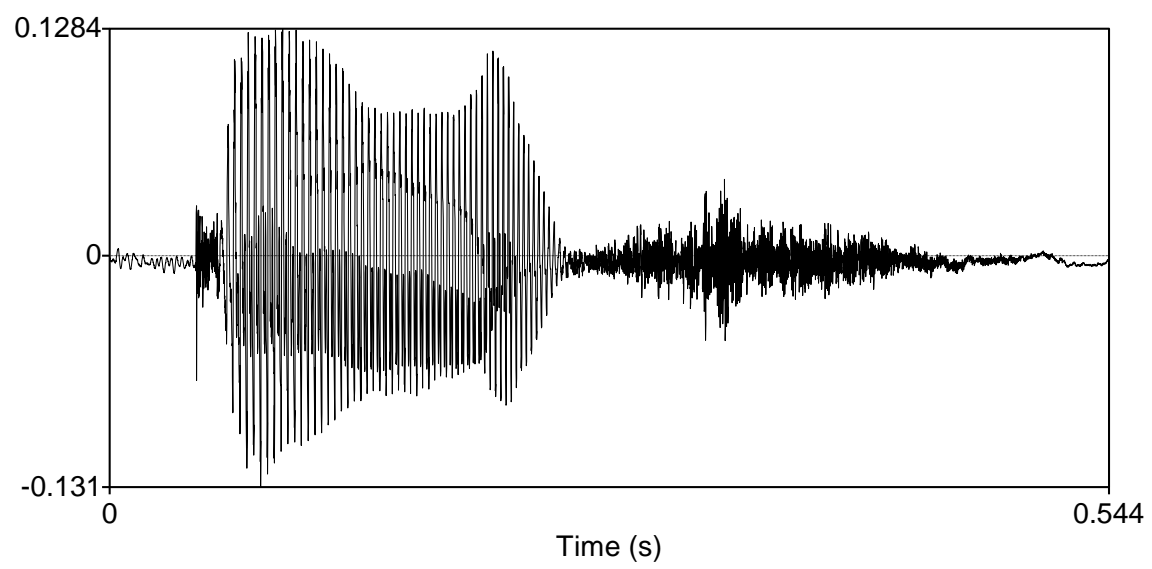

Figure 13: /h/ as coda in tuj 'shoot!'

Similar phonetic and phonological features are also reported for other Mesoamerican and Mixean languages. Contrastive underlying voiced fricatives are generally absent in Mesoamerican languages (Campbell et al. 1986) and retroflexed fricatives also occur in other Mixean languages (Campbell et al. 1986; Van Haitsma 1976), but not in Isthmus Mixe (Dieterman 2008). In regard to the fricatives Chuxnabán Mixe represents thus a typical Mixean and Mesoamerican language.

\subsection{Affricates ts, t $\int$}

Chuxnabán Mixe has two affricates, one in alveolar and one in postalveolar position: /ts, t $\int$ /. The postalveolar affricate generally results from morpheme-induced palatalization and is not treated as a phoneme in some descriptions of other Mixean languages (Dieterman 2008). It has been included here because morpheme-induced palatalization of other consonants results in having an onglide and an offglide and affecting surrounding vowels, and this is not always the case with the postalveolar affricate. Moreover, the postalveolar affricate is not always evidently a result of morpheme-induced palatalization. The alveolar affricate has three allophones: voiceless, voiced, and a voiceless sibilant [s]. The postalveolar affricate has a voiceless and a voiced allophone.

$$
\begin{array}{lll}
/ \mathrm{ts} / & \rightarrow & {[\mathrm{ts}, \mathrm{dz}, \mathrm{s}]} \\
/ \mathrm{t} f / & \rightarrow & {\left[\mathrm{t} f, \mathrm{~d}_{3}\right]}
\end{array}
$$

Both affricates are voiced after nasals and glides word-medially and in word-initial clusters. They are also voiced intervocalically after plain and interrupted vowels and word-medially if affected by palatalization. Word-final affricates are always voiceless. The voiceless alveolar sibilant occurs in clusters with $/ \mathrm{k}, \mathrm{p}, \mathrm{m} /$ word-finally and before $/ \mathrm{n} /$ word-initially and word-medially.

$\begin{array}{llll}\text { Voiceless alveolar affricate: } & \underline{\text { uujtsatsëm }} & \text { 'wild boar' } & ->\left[\mathrm{u}^{\mathrm{h}} \text { 'tsa'dzim] }\right. \\ & \underline{\text { tsip }} & \text { 'war' } & ->[\mathrm{tsip}] \\ & \underline{\text { mits }} & \text { 'cat' } & ->[\mathrm{mits}] \\ \text { Voiced alveolar affricate: } & \underline{\text { uujtsatsëm }} & \text { 'wild boar' } & ->\left[\mathrm{u}^{\mathrm{h}} \text { 'tsa'dzim] }\right.\end{array}$




\begin{tabular}{|c|c|c|c|}
\hline \multirow{5}{*}{ Voiceless alveolar sibilant: } & $\underline{\text { wiintsëën }}$ & ‘owner’ & -> [wi:n'dzi̇:n] \\
\hline & ntsookypy & 'I love you' & $->\left[n d z o: j k^{j} p^{j}\right]$ \\
\hline & ja'anchukts & 'ant' & $->\left[\mathrm{ha}^{2} \mathrm{an}^{\prime} \mathrm{d}\right.$ zuks $]$ \\
\hline & $\underline{t s a p t s}$ & 'red' & $->[$ tsaps $]$ \\
\hline & jatsnxëëwj & 'My name is' & -> [hasn'zë:wh] \\
\hline \multirow[t]{3}{*}{ Voiceless post-alveolar affricate: } & $\underline{\text { tiinch }}$ & 'gut' & $->\left[\right.$ ti:nt $\left.\int\right]$ \\
\hline & champ & 'now' & $\left.->\left[\mathrm{t} \int a m p\right\urcorner\right]$ \\
\hline & kachypyaajk & 'rib' & $->\left[\mathrm{kajt}^{\mathrm{l}} \mathrm{pja}_{\mathrm{:}}^{\mathrm{h}} \mathrm{k}\right]$ \\
\hline \multirow[t]{3}{*}{ Voiced post-alveolar affricate: } & ja'anchukts & 'ant' & $->\left[\right.$ ha $^{2}$ an'dzuks $]$ \\
\hline & $\underline{\text { ni’ichëëjk }}$ & 'husband' & $->\left[n i^{2} i^{\prime} d \dot{i}^{, h} k\right]$ \\
\hline & mëja'aychëëjk & ‘old person’ & $->\left[\operatorname{miha}^{\mathrm{T}} \mathrm{aj} \mathrm{j}^{\prime} \mathbf{3}_{\mathbf{i}^{\mathrm{h}}}^{\mathrm{h}} \mathrm{k}\right.$ \\
\hline
\end{tabular}

The voiceless alveolar affricate rather than the sibilant occurs after /n/ word-finally.

Voiceless alveolar affricate: $\quad$ wiints $\quad$ 'blind' $\quad->$ [wints]

Occasionally, only partial voicing occurs in the initial segment, as in Figure 14. Allophonic voiced affricates are also found in other Mesoamerican languages (Campbell et al. 1984), and similar allophonic variations have been reported for other Mixean languages (Van Haitsma 1976). Dieterman (2008) also notices partial voicing of affricates in the related Isthmus Mixe. Thus, Chuxnabán Mixe is again a typical Mixean and Mesoamerican language in this regard.

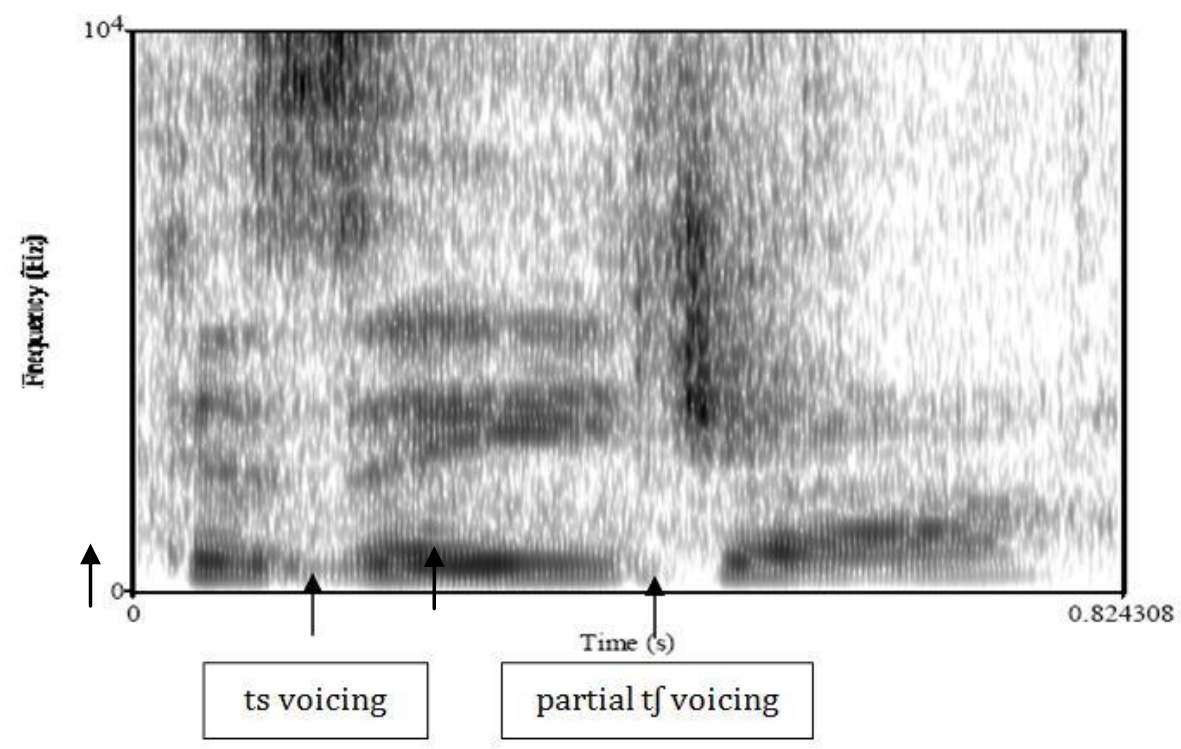

Figure 14: Voicing of /ts/ and partial voicing of /t $\mathrm{f} /$ in këtseychaa 'chicken egg'

It could be argued that the affricates are simply sequences of two phonemes rather than a single phoneme. Dieterman (2008) offers several reasons for why the affricate /ts/ functions as a unit rather than as a combination of two phonemes in Isthmus Mixe. Her arguments include: (a) /ts/ 
occurs word-initially in roots, and there are no consonant clusters word-initially without prefixing, (b) coda clusters are limited to two consonants, (c) both elements of the affricate are pronounced syllable-finally, which is not always the case for consonant clusters, and (d) [s] is merely an allophone of /ts/. While (a) and (d) are also true for Chuxnabán Mixe, (b) and (c) are not. However, (a) and (d) represent enough evidence to treat the affricates a phonemic units.

\subsection{Nasals m, n}

There are two nasals in bilabial and in alveolar position: /m, n/. The bilabial nasal has two allophones, voiced and voiceless. The alveolar nasal has three allophones: voiced alveolar, voiceless alveolar, and voiced velar. The voiceless nasals occur word-finally after the voiceless obstruents /p, t, k, x, ts, ch/, as in Figure 15. The velar nasal occurs before /k/ in any cluster.

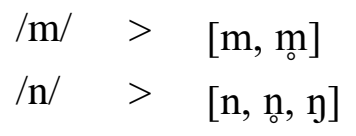

\begin{tabular}{|c|c|c|c|}
\hline \multirow[t]{3}{*}{ Voiced bilabial nasal: } & $\underline{\text { mits }}$ & 'cat' & $>$ [mits $]$ \\
\hline & $\underline{p a^{\prime} a m}$ & 'illness' & $>\left[\mathrm{pa}^{2} \mathrm{am}\right]$ \\
\hline & $\underline{\text { mamokx }}$ & 'fifteen' & $>$ [ma'moks $]$ \\
\hline \multirow[t]{3}{*}{ Voiceless bilabial nasal: } & poxm & 'spider' & $>$ [posm $]$ \\
\hline & po'tmp & 'summer' & $>\left[\mathrm{po}^{2} \operatorname{tmp}^{\urcorner}\right]$ \\
\hline & $\underline{a^{\prime} \operatorname{chmp}}$ & 'custard apple' & 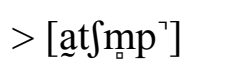 \\
\hline \multirow[t]{3}{*}{ Voiced alveolar nasal } & $\underline{n e ̈ t s}$ & ‘armadillo’ & $>[$ nits $]$ \\
\hline & joon & 'bird' & $>$ [ho:n $]$ \\
\hline & $\underline{\text { nanuelë }}$ & 'grandmother' & $>$ [na'nwelì] \\
\hline \multirow[t]{3}{*}{ Voiceless alveolar nasal: } & $\underline{i i j x n}$ & 'mirror' & $>\left[i_{\sim}^{i}:{ }_{S}^{h} n\right]$ \\
\hline & $\underline{\text { kaajpn }}$ & 'village' & $>\left[\mathrm{ka}:{ }^{\mathrm{h}} \mathrm{pn}_{\mathrm{a}}\right]$ \\
\hline & $\underline{\text { kaychyakn }}$ & 'kitchen' & $>\left[\mathrm{kaj}^{\prime} \mathrm{d} 3^{\mathrm{j}} \mathrm{akn}\right]$ \\
\hline \multirow[t]{3}{*}{ Voiced velar nasal: } & $\underline{\text { maank }}$ & 'son’ & $>$ [ma:nk $]$ \\
\hline & u'unkëch & 'children' & $>\left[u^{2}\right.$ ungit $\left.\int\right]$ \\
\hline & juunk & 'sheep' & $>$ [hu:yk] \\
\hline
\end{tabular}

Duration measurements of nasals in word-initial and word-final position, as well as those affected by palatalization, have not revealed a clear pattern. A total of 276 tokens were measured in 23 different words for 4 speakers, two females and two males. Each word was recorded three times in a carrier phrase. ${ }^{7}$ The words only contained the voiced allophones. While for some

\footnotetext{
${ }^{7}$ The measured words include $\underline{\operatorname{maa}}$ 'where', $\underline{\operatorname{mok}}$ 'corn', $\underline{\operatorname{mox}}$ 'stomach', $\underline{\text { mits }}$ 'cat', $\underline{\mathrm{kam}}$ 'field', $\underline{\mathrm{cham}}$ 'now', $\underline{\mathrm{tsim}}$

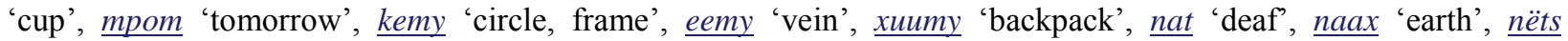
'armadillo', nën 'gum of the mouth', kaan 'salt', pan 'plant to be planted', $\underline{\text { xun }}$ 'sour, bitter', $\underline{\text { xany }}$ 'cloudy (water)', yeny 'tall', $\underline{\text { mony }}$ 'short, weak', $\underline{\text { muny }}$ 'potato'.
} 
speakers word-initial nasals are longer than word-final nasals, for others the opposite is true. The results show great variation within words, speakers, and even within the same word and speaker. Nevertheless, palatalized nasals tend to be longer with some exceptions. The results are illustrated in Figures 16 and 17.

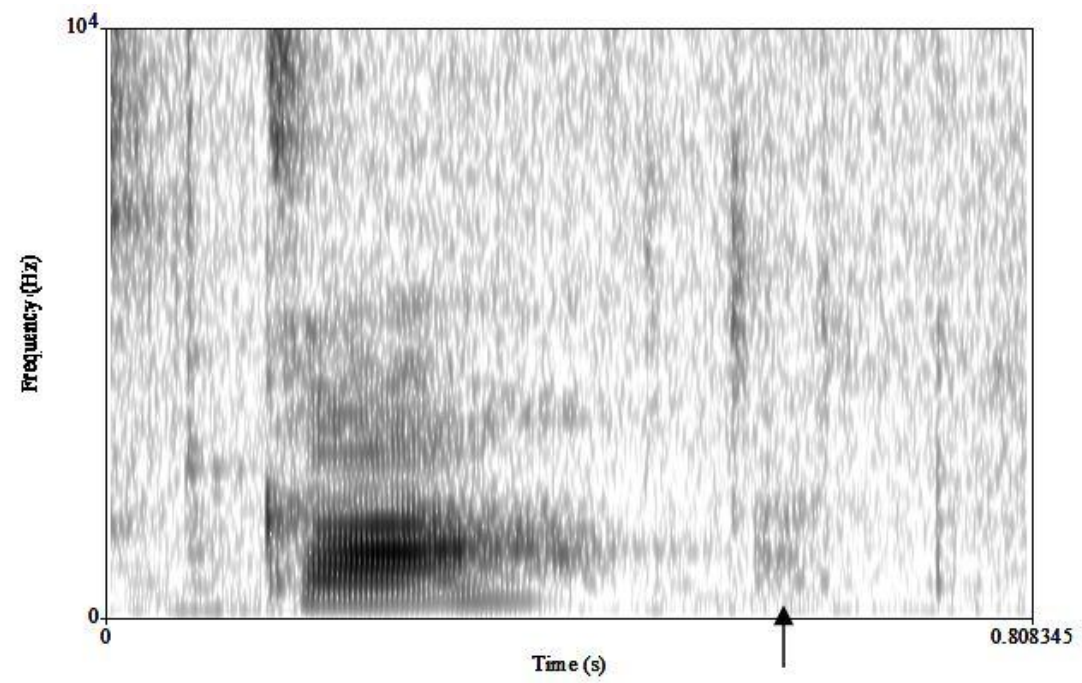

Figure 15: Voiceless nasal in kaajpn 'village'

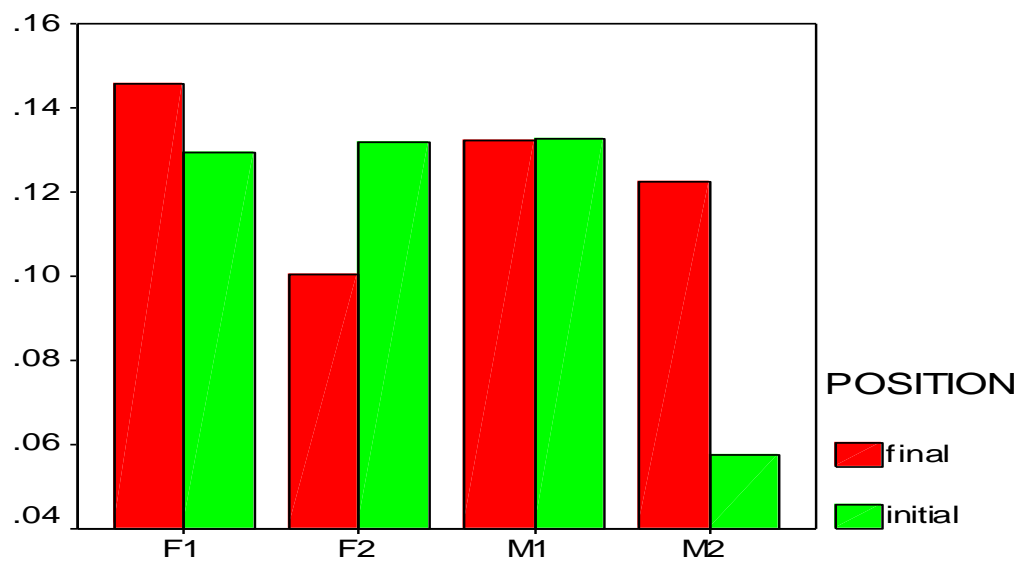

SPEAKER

Figure 16: Duration of $/ \mathrm{m} /$ in initial and final position (palatalized tokens excluded) $\mathrm{F}=$ female; $\mathrm{M}=$ male 


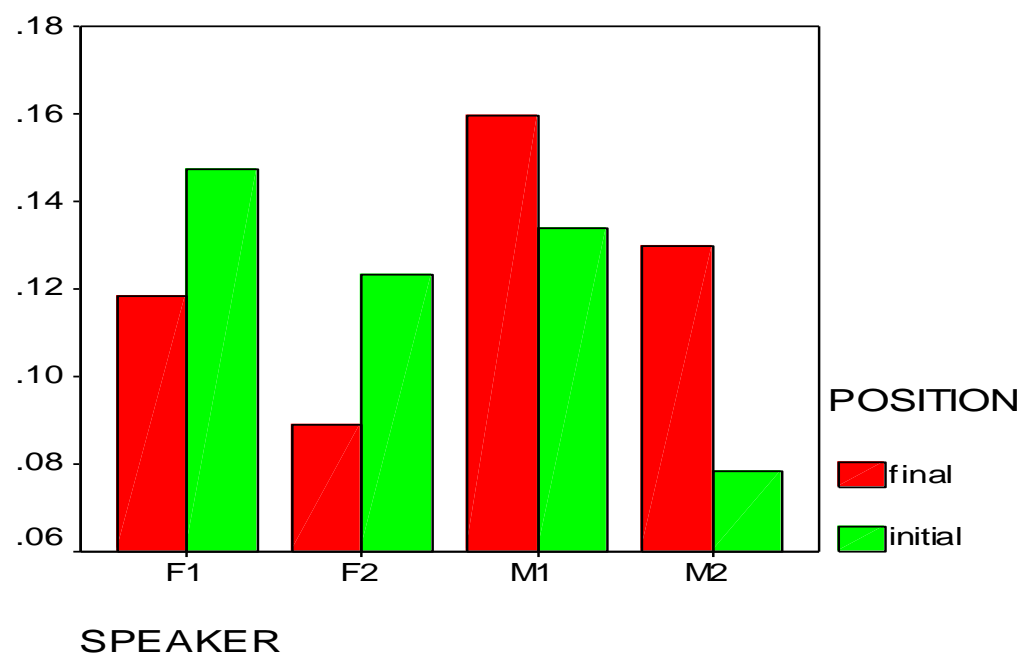

Figure 17: Duration of /n/ in initial and final position (palatalized tokens excluded) $\mathrm{F}=$ female; $\mathrm{M}=$ male

Figures 16 and 17 illustrate that final nasals are not longer than initial nasals and that only two speakers, F2 and M2, show the same pattern for $/ \mathrm{n} /$ and $/ \mathrm{m} /$. Van Haitsma (1976) reports longer duration of initial nasals when a person prefix $n$-, $m$ - occurs in a word with an initial nasal. This has not been tested here. Campbell et al. (1984) indicate that devoicing of nasals in final position is also found in other Mesoamerican languages. Thus, Chuxnabán Mixe is typical in this regard.

\subsection{Glides w, y}

Glides occur in bilabial and palatal position: /w, y/. They only have one voiced allophone each, since they do not occur in environments that would trigger devoicing. Crawford (1963) notes a voiced labio-dental and a voiceless bilabial fricative allophone for the bilabial glide /w/ in Totontepec Mixe; no such allophones have been found in Chuxnabán Mixe.

$/ \mathrm{w} / \quad \rightarrow \quad[\mathrm{w}]$

$/ \mathrm{y} / \quad \rightarrow \quad[\mathrm{y}]$

Bilabial glide:

Palatal glide:

$\begin{array}{lll}\underline{\text { kow }} & \text { 'guitar' } & ->[\mathrm{kow}] \\ \underline{\text { waay }} & \text { 'hair' } & ->[\mathrm{waj}] \\ \underline{\text { koy }} & \text { 'pillow' } & \rightarrow[\mathrm{koj}] \\ \underline{\text { yok }} & \text { 'neck' } & \rightarrow[\mathrm{jok}]\end{array}$

Although the palatal glide phoneme /y/ is different from morpheme-induced suprasegmental palatalization, it can similarly cause palatalization of adjacent segments, in addition to voicing, as in the following example.

ney 'twisted' + paatëp 'to find' $\quad \rightarrow$ neypyaatëp [nej'bja:tip] 'to connect'

Morpheme-induced palatalization differs from the examples above in that it occurs only at word-edges, and it does not trigger voicing of adjacent segments. 
When comparing the palatal glide /y/ to the high front vowel /i/ the second formant (F2) is lower. This indicates a more retracted tongue position for $/ y /$, as expected. F2 measurements for /u/ and /w/ reveal lower numbers for the bilabial glide /w/ showing greater lip rounding. The F2 measurements demonstrate that the two glides are clearly different from the high vowels. Measurements were only taken for one female speaker in twenty-four tokens including word-initial and word-final glides. No difference was noted with regard to prosodic position.

\subsection{Suprasegmental palatalization}

Palatalization in Chuxnabán Mixe, as in other Mixean languages (Hoogshagen 1997; Schoenhals 1982; Van Haitsma 1976; Dieterman 2008), is a suprasegmental process affecting not only the palatalized consonant, but adjacent vowels as well. This is perceived as an onglide and an offglide. Furthermore, it is manifested by a change in the formant structure of adjacent vowels lowering F1 and raising F2. The latter indicates fronting. One exception is the palatalized palatal glide /y/, because it does not undergo any changes with morpheme-induced palatalization (Dieterman 2008; Jany 2006). In addition to changes in the vowel quality of surrounding vowels, the release burst in palatalized consonants is different. While it shows an even distribution of turbulence in a non-palatalized consonant, the distribution of the release burst of a palatalized consonant stays in the higher frequencies. This is illustrated in Figures 18 and 19.

Dieterman's (2008) detailed study of palatalization in the related Isthmus Mixe shows that this phenomenon is best described as secondary palatalization: the addition of a high front tongue position as secondary articulation occurring simultaneously with the primary consonantal articulation (Ladefoged 1993, Keating 1993). While secondary palatalization manifests as a secondary articulation of the consonants $/ \mathrm{p}, \mathrm{m}, \mathrm{h},{ }^{?}, \mathrm{w} /$, it also changes the primary position of the alveolar and velar consonants $/ \mathrm{t}, \mathrm{k}, \mathrm{x}, \mathrm{ts}, \mathrm{n} /$ moving them toward the palatal region (Dieterman 2008). This is most apparent for the alveolar affricate $t s$ which also changes its orthography to <ch> to represent a postalveolar affricate, as in the following example:

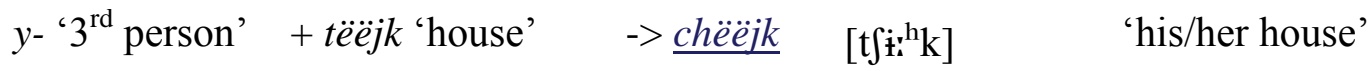

Morpheme-induced suprasegmental palatalization occurs at word-edges, such as when the third-person possessive prefix $y$-is added, as in the example above. Given that all consonants are found word-initially, all consonants can be palatalized. ${ }^{8}$ Dieterman (2008) notes that there is no other language family where secondary palatalization occurs for the entire consonant inventory manifesting a morpheme. The same principles as in Isthmus Mixe are found in Chuxnabán Mixe.

\footnotetext{
${ }^{8}$ In the orthography palatalization is represented by a palatal glide /y/ following the palatalized consonant, except for the palatalized affricate which is represented as $\langle\mathrm{ch}\rangle$.
} 


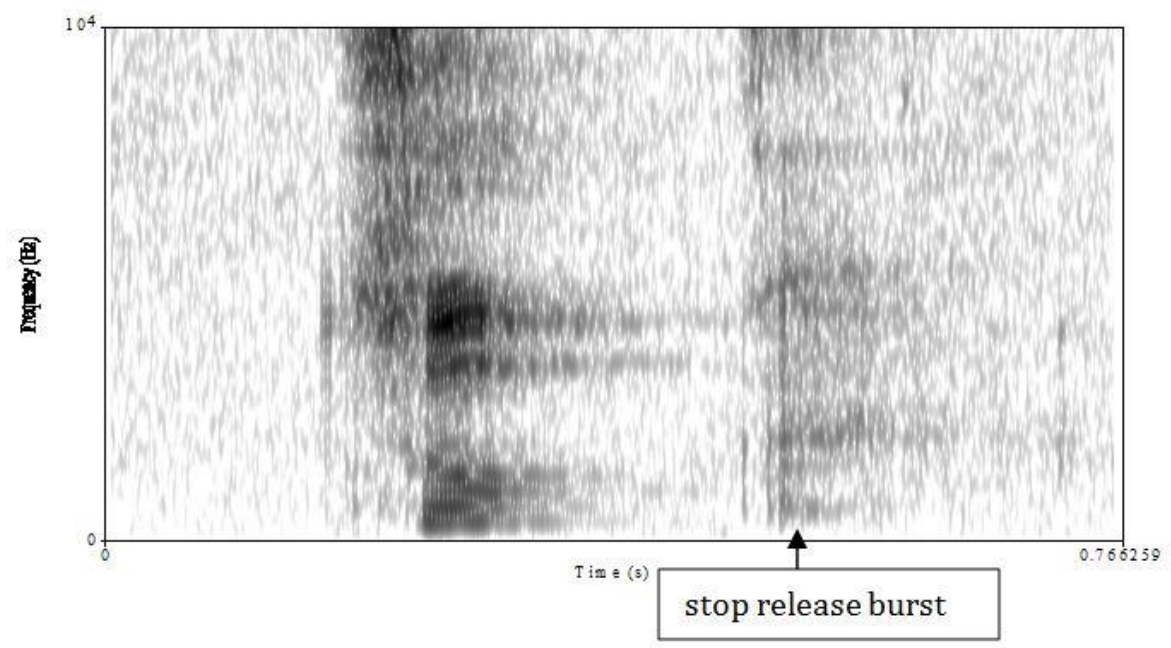

Figure 18: Spectrogram of $\underline{t s u k}$ 'mouse' with non-palatalized stop

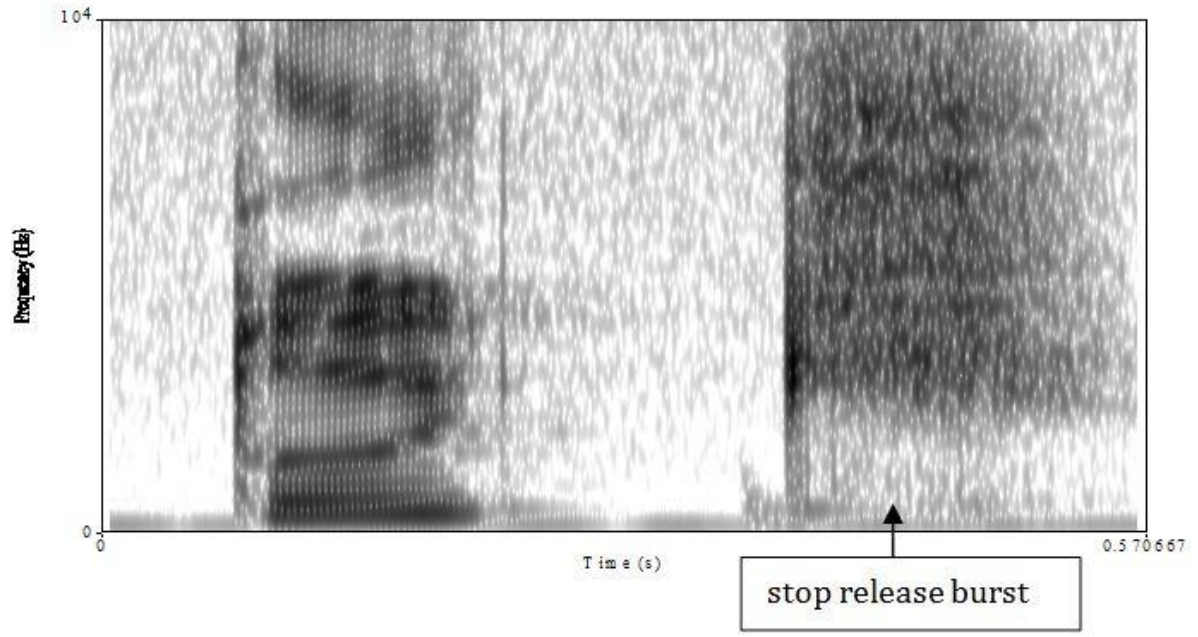

Figure 19: Spectrogram of tuky 'to cut' with palatalized stop

The phoneme /y/ is distinct from morpheme-induced secondary palatalization. This is apparent because it does not palatalize the person prefixes $n$ - and $m$-.

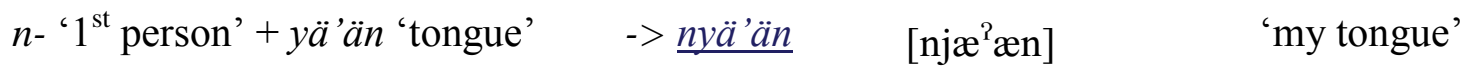

However, the third person prefix $y$-palatalizes a following root-initial nasal:

$y$-' $3^{\text {rd }}$ person' + niixuy 'shirt' $\quad->$ nyiixuy $\quad$ [ni:'zuj]

Chuxnabán Mixe also has a palatalization process which occurs in compounds word-medially and is not morpheme-induced. If a word ending in the palatal glide precedes another word in a compound, the first segment of the second word is palatalized and voiced.

tëy 'truth' + kaapxp' $\quad$-> tëykyaapxp $\quad$ [tij'gja:psp] 'to tell the truth' to speak' 
Phonetically, this process is different from morpheme-induced palatalization in that it also causes voicing of the following segment. The same occurs with word-final palatalized consonants, but only if they are voiced.

$$
\begin{array}{lllll}
\text { mony 'fair, pale' } & + \text { pu'uts 'yellow } & \rightarrow \text { monypyu'uts } & {\left[\mathrm{moj}^{\prime} \mathrm{bju}^{\mathrm{T}} \mathrm{uts}\right]} & \text { 'fair yellow' } \\
\text { teky 'leg' } & + \text { tu'uk'one' } & ->\text { tekychu'uk} & {\left[\mathrm{tej}^{\mathrm{j}} \mathrm{t} \mathrm{t} \mathrm{u}^{\mathrm{h}} \mathrm{uk}^{\mathrm{h}}\right]} & \text { 'one-legged' }
\end{array}
$$

Palatalized consonants are affected by and trigger voicing and devoicing of adjacent segments in the same way as non-palatalized consonants, i.e. only voiced consonants can cause voicing and only voiceless ones devoicing.

Final devoicing of palatalized nasal: pixyny 'cotton' $\quad->\left[\right.$ pi $\left.\int^{\mathrm{j}} \mathrm{j}\right]$

If the second word in a compound begins with a palatal glide, palatalization does not carry over to the previous segment:

$\begin{array}{llllll}\text { tsuxk } & \text { 'green' } & + \text { yëk'black' } & \rightarrow \text { tsuxkyëk } & \text { [tsusk'jik }] & \text { 'dark green' } \\ \text { tsa'am } & \text { 'plantain' } & + \text { yok'neck' } & \rightarrow \text { tsa'amyok } & \text { [tsa'am'jok }] & \text { 'plantain neck' }\end{array}$

This is different from morpheme-induced final palatalization which carries over to a segment to the left and to the right and affects entire consonant clusters. Moreover, it does not trigger voicing. The same has been observed in Isthmus Mixe (Dieterman 2008).
עё'ё mtsoojkp
[jï ${ }^{\mathrm{i}} \dot{\mathrm{i}} \mathrm{mdzo}:^{\mathrm{h}} \mathrm{kp}$ ]
'he/she loves you'
yё'ё chöojkypy
$\left[\mathrm{ji}^{2} \dot{\mathrm{i}} \mathrm{t} \int \varnothing^{\mathrm{h}} \mathrm{jk}^{\mathrm{j}} \mathrm{p}^{\mathrm{j}}\right]$
'he/she loves him/her'

\subsection{Phonological processes affecting consonants}

There are five phonological processes affecting or involving consonants: (1) obstruent voicing, (2) sonorant devoicing, (4) nasal place assimilation, (4) consonant cluster reduction, and (5) glottal stop insertion. (1) and (2) are similar in that they both can be seen as voicing assimilation.

Seven out of the eleven consonants are obstruents: /p, t, k, ? $, \mathrm{x}, \mathrm{h}, \mathrm{ts} /$. Obstruent voicing occurs after nasals and glides, i.e. after sonorants, except word-finally, and it occurrs intervocalically, except after aspirated and glottalized vowel nuclei. Obstruent clusters and obstruent geminates are not voiced.

Voicing after nasal:

Voicing after glide:

Voicing intervocalically:

Voicing intervocalically

\begin{tabular}{|c|c|c|}
\hline ankëëxp & 'above' & $->$ [aך'gí:sp $\left.{ }^{\urcorner}\right]$ \\
\hline puиуруаajk & 'femur' & $->\left[p_{i j}{ }^{\prime} b^{j} a^{h^{h}} k\right]$ \\
\hline$\underline{\operatorname{axux}}$ & 'garlic' & -> [a'zus] \\
\hline pojënё & 'fast' & -> ['pohinì $]$ \\
\hline pa'akuujts & 'sweet herb' & $->\left[\mathrm{pa}^{\mathrm{T}} \mathrm{ag}^{\prime} \mathrm{u}^{\mathrm{h}} \mathrm{ts}\right]$ \\
\hline
\end{tabular}

Voicing after interrupted vowels: 
No voicing word-finally: $\quad$ maank $\quad$ 'son' $\quad->\left[\mathrm{ma}^{\mathrm{n}} \mathrm{k}^{\mathrm{h}}\right]$

No voicing after glottalized vowel: jyüuka'të 'they lived' $\quad->\left[\mathrm{hjy}: \mathrm{g}^{12} \mathrm{a}^{2} \mathrm{ti}\right]$

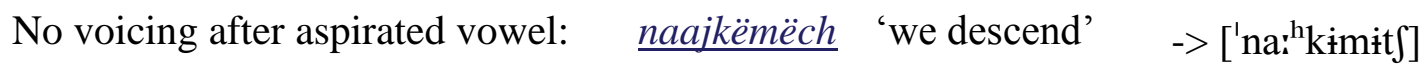

No voicing in cluster: $\quad$ tuktuujk 'eight' $\quad \rightarrow\left[\right.$ tuk $\left.^{\mathrm{hl}} \mathrm{tu}^{\mathrm{h}}{ }^{\mathrm{h}} \mathrm{k}^{\mathrm{h}}\right]$

No voicing in geminate: jappëk 'there' $\quad \rightarrow$ ['hap:ik $\left.{ }^{\mathrm{h}}\right]$

The voicing pattern can be explained with one phonological rule. Voiceless obstruents are voiced if they occur between two voiced segments:

[-sonorant] [-voice] -> [+voice] / [+voice $] \_[+ \text {[+voice }]$

Word-edges, aspirated vowels, and glottalized vowels are regarded as voiceless environments, while interrupted vowels act as a voiced segment. This can be explained with the laryngeal timing of breathiness and glottalization in these vowel nuclei. In breathy and in glottalized vowels breathiness or creakiness occurs in the last portion of the vowel, hence creating a voiceless environment on the right edge of the nucleus, while in interrupted vowels creakiness occurs in the middle portion of the vowel.

Voicing at word-edges occurs only in shortened forms where the first syllable has been dropped. This shows that voicing occurs prior to shortening.

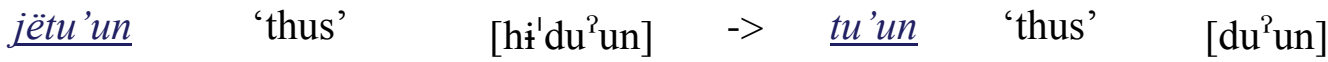

Morpheme-induced palatalization at word-edges does not cause voicing, while word-medial palatalization does.

$\begin{array}{llll}\text { No voicing: } & y-+ \text { pak } & \rightarrow \text { pyak } & \text { 'his dove' } \\ \text { Voicing: } & t \ddot{e} y+\text { kaapxp } & \rightarrow \text { tëygyaapxp } & \text { 'to tell the truth' } \quad \text { [tij'gja:psp] }\end{array}$

The lack of voicing in morpheme-induced palatalization can be explained by metathesis \#yCV -> \# $\mathrm{CyV}$, hence leaving a voiceless environment to the left. However, the voicing rules do not always apply in the same way, as there is token and speaker variation. This points to sound in change in progress (Jany, to appear), similar to patterns seen in Sayula Popoluca (Rhodes 2004).

There are four sonorants, two nasals and two glides. Sonorant devoicing is also based on voicing assimilation. Sonorants devoice word-finally in clusters and word-initially before obstruents, i.e. in voiceless environments:

[+sonorant] [-syllabic] [+voice] -> [-voice] / [-voice] __ [-voice]

The same as with the voicing rules, word-edges are regarded as voiceless environments.

\begin{tabular}{|c|c|c|c|}
\hline Devoicing: & $\underline{\text { kaajpn }}$ & ‘village’ & [ka: $\left.{ }^{\mathrm{h}} \mathrm{pn}\right]$ \\
\hline & a'chmp & 'custard apple' & [a $\left.\underset{\sim}{\operatorname{at}} \int \mathrm{mp} p\right]$ \\
\hline & $\underline{\text { njot }}$ & 'my stomach' & {$\left[\right.$ nhot $\left.^{\mathrm{h}}\right]$} \\
\hline
\end{tabular}


Glides do not occur in a voiceless environment; therefore they are never devoiced. Palatalized and non-palatalized consonants are equally affected by the voicing and devoicing rules.

pixyny 'cotton' [pi

tëyimpyu'uk 'tadpole' [tijim' $\left.\mathrm{b}^{\mathrm{j}} \mathrm{u}^{\mathrm{T}} \mathrm{uk}\right]$

The vowels of clitics do not cause voicing, but they prevent final devoicing:

kachy 'basket' [kat $\left.\int^{\mathrm{j}}\right] \quad \quad \rightarrow \underline{k a c h y=\ddot{e} n}$ 'in the basket' ['kat $\left.\int^{\mathrm{j} i n}\right]$ (=ёn is a locative)

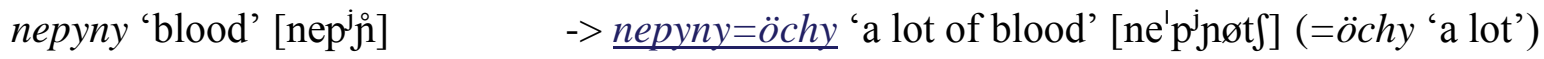

The same as with obstruent voicing, there is some token variation indicating a sound change in progress (Jany, to appear). Obstruent voicing and sonorant devoicing are common to Mesoamerica and regarded as two defining traits of this linguistic area (Campbell et al. 1986). They have also been noted in a number of other Mixean languages (Bickford 1985; Crawford 1963; Dieterman 2008; Ruiz De Bravo Ahuja 1980; Schoenhals 1982; Van Haitsma 1967; Wichmann 1995). Hence, Chuxnabán Mixe represents a typical Mesoamerican and Mixean language. Van Haitsma (1976) mentions occasional word-final voicing of obstruents after long and interrupted vowels, in certain word-final clusters, and in cases where stem-final /w/ is dropped before /p/. Word-final voicing does not occur in Chuxnabán Mixe.

Nasal place assimilation has also been reported for a number of Mixean languages (Crawford 1963; Dieterman 2008; Schoenhals 1982; Van Haitsma 1967). Van Haitsma (1976) states that nasal place assimilation occurs in words other than verbs, and that there is some speaker variation. In Chuxnabán Mixe, a morpheme-final alveolar nasal /n/ sometimes assimilates to the following stop in place of articulation. This can be summarized as follows:

$/ \mathrm{n} /=[\mathrm{n}] /[\mathrm{t} /$
$/ \mathrm{n} /=[\mathrm{m}] /[\mathrm{p} /$
$/ \mathrm{n} /=[\mathrm{y}] /$

tun 'to work', but tun $+=p \ddot{e} \quad \rightarrow \underline{\text { tumpë }}$ 'worker'

miin 'to come', but miin $+-p \quad \rightarrow$ miimp 'I come'

wiin 'eye', but wiin + ki'ix $\quad->\underline{\text { wiinki'ix }}$ 'dark circles around eyes' [wi:y'gi'is]

Following Dieterman (2008), the alveolar nasal could be regarded as an archiphoneme in morpheme-final position, always assimilating in place of articulation to the following segment. Dieterman (2008) shows for the related Isthmus Mixe that nasal place assimilation only occurs in morpheme-final position, preserving the contrast found in the person markers $n$ - and $m$ word-initially. Generally, the same occurs in Chuxnabán Mixe.

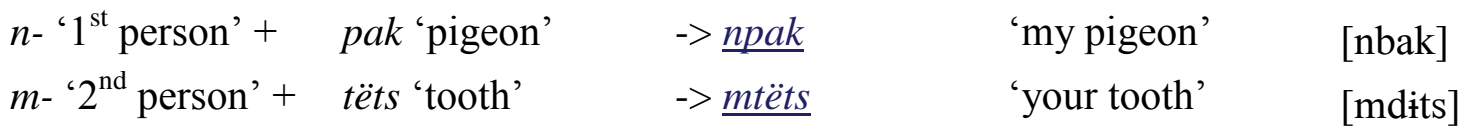


However, occasionally nasal place assimilation is also noted in this position. Thus, the same as with the (de)voicing rules, the irregular patters can be viewed as sound change in progress.

$n$-'1 ${ }^{\text {st }}$ person' + pa'ak'sweet' -> npa'ak 'my sweet' [mba'ak]

Nasal place assimilation does not occur with the bilabial nasal $/ \mathrm{m} /$.

\begin{tabular}{|c|c|c|c|c|}
\hline poxm & 'spider' + ta'aky 'to spin' & -> poxmta'aky & 'spiderweb' & {$\left[\operatorname{posm}^{\prime} \mathrm{da}^{\mathrm{P}} \mathrm{ajk}^{\mathrm{j}}\right]$} \\
\hline atsëm & 'pig' + tsu'uch 'meat' & -> atsëmtsu'uch & 'pork meat' & [adzim'dzu' $\left.{ }^{2} u t \int\right]$ \\
\hline tsa'am & ,plaintain' + kepy 'tree' & -> tsa'amkepy & 'plaintain part' & {$\left[\operatorname{tsa}^{2} \operatorname{am}^{\prime}\right.$ gep $\left.^{\mathrm{j}}\right]$} \\
\hline
\end{tabular}

Consonant cluster reduction is a phonological process that occasionally occurs in compounding, in particular when the final consonant of the first word is the same as the initial consonant of the second, i.e. for underlying geminates.

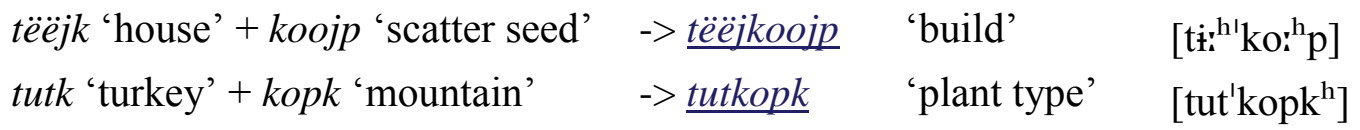

Similarly, Van Haitsma (1976) describes geminate cluster reduction for the related San Juan El Paraíso Mixe and affirms that word-initially underlying geminates resulting form prefixing of the person markers $n$ - and $m$ - are longer in duration than single consonants. Longer duration for underlying geminates also occurs in Chuxnabán Mixe, as in chamën 'now' ['t faminn]. Other types of consonant clusters also get reduced. Such reductions are common in numerals.

$\begin{array}{llll}\text { taxk 'four' } & + \text { tuujk 'base for five' } & ->\underline{\text { taxtuujk }} & \text { 'nine' } \\ j x c h i k x \text { 'forty' } & & ->\text { jxikx } & \text { 'forty' } \\ \text { mëkoxk'five' } & +i \text { 'px 'twenty' } & ->\underline{\text { mëko'px }} & \text { 'hundred' } \\ \text { maajk 'ten' } & + \text { tëkëëk'three' } & ->\underline{\text { maajtëkëëk }} & \text { 'thirteen' }\end{array}$

In general, however, there is no cluster reduction in compounding, contrary to what Dieterman (2008) found for Isthmus Mixe where compound words drop the final consonant of the first word.

\begin{tabular}{|c|c|c|}
\hline tsaajp 'heaven' + tëëjk 'house' & -> tsaajptëëjk 'church' & {$\left[\right.$ tsa: $\left.^{\mathrm{h}} \mathrm{p}^{\prime} \mathrm{ti:}^{\mathrm{h}} \mathrm{k}^{\mathrm{h}}\right]$} \\
\hline teky 'foot' + jot 'neck' + paajk 'bone' & -> tekyjotpaajk 'metatarsus' & {$\left[\operatorname{tek}^{\mathrm{j}} \mathrm{h}^{\mathrm{j}} \mathrm{ot}^{\mathrm{l}} \mathrm{pa}^{\mathrm{h}} \mathrm{k}^{\mathrm{h}}\right]$} \\
\hline mamokx 'fifteen' + tu'uk 'one' & -> mamokxtu'uk'sixteen' & [mamokș'tu $\left.{ }^{2} u k\right]$ \\
\hline
\end{tabular}

Another phonological process involves the insertion of a segment. Vowel-initial words generally add an initial glottal stop to avoid onsetless syllables. It is obligatorily inserted in compounding where two adjacent vowels would occur, and when a prefix is added to a vowel-initial word.
$y a a+i i x+m a ' t p \ddot{e}$
-> yaa'iixma'tpë 'ghost'
[ja: $\left.{ }^{2} i s^{\prime} m a{ }^{2} \operatorname{tpi}\right]$
kuuktaa + ooyë
-> kuuktaa'ooyë 'to improve' [ku:kta:' o:ji 


$$
\begin{array}{lll}
n-+a^{\prime} t & ->\underline{n^{\prime} a^{\prime} t} \text { 'my louse' } & {\left[\mathrm{n}^{2} \mathrm{a}^{\mathrm{T}} \mathrm{t}\right]} \\
m-+u k & ->\underline{m^{\prime} u k} \text { 'your dog' } & {\left[\mathrm{m}^{2} \mathrm{uk}\right]}
\end{array}
$$

\subsection{Phonological adaptation of Spanish loans}

Spanish loanwords generally experience the same phonological processes as words of Mixe origin. However, given that Spanish has additional phonemes not found in Chuxnabán Mixe, such as contrastive voiced stops, the voicing rules do not always apply. For instance, in Spanish loans word-initial and word-final voiced stops may occur, as well as intervocalic voiceless stops.

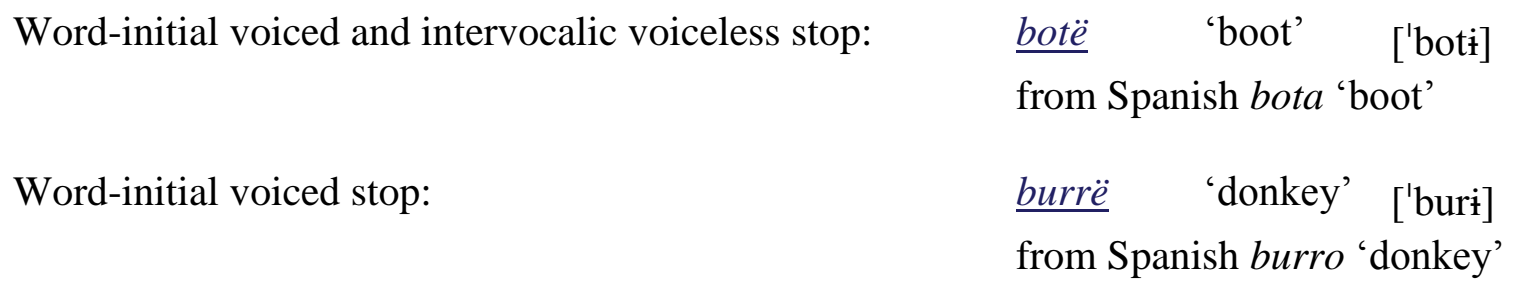

However, phonological processes triggered by affixing, such as obstruent voicing and metathesis, equally apply to Spanish loans.

Obstruent voicing: carton 'box'+ koch 'in' $\quad$-> cartonkoch 'in the box' [karton'gotf] from Spanish cartón 'box'

Metathesis: $\quad y$ - 'his, her' + burrë 'donkey' $\quad$-> byurrë 'his donkey' ['bjurì]

In compounding, however, the voicing rules do not always apply.

cerë 'wax' from Spanish cera + pa'ak'sweet'_ -> cerëpa'ak 'honey' [se:ri'pa ak]

\section{The Vowel System}

The Mixean languages vary greatly in their vowel systems (Suslak 2003). For instance, while Totontepec Mixe has nine phonemic vowels (Schoenhals 1982), only six are reported for Coatlán Mixe (Hoogshagen 1959, 1997). Nevertheless, all Mixean languages show a phonemic vowel length distinction and a phonemic phonation contrast between plain, aspirated, glottalized, and interrupted vowels. Chuxnabán Mixe has nine vowel qualities [a, e, i, o, u, i, æ, ø, y]. Three of the vowel qualities, $[\mathfrak{x}, \varnothing, \mathrm{Y}]$, generally do not show a phonemic contrast since they result from suprasegmental palatalization and interdialectal borrowing. Two of these vowels, $[\varnothing]$ and $[\mathrm{Y}]$, always occur in palatalized environments, mostly in stem alternations of verbs. The third marginal vowel [æ] shows some variation between speakers and tokens of the same word. For example, some instances of maajtsk 'two' have pronunciations closer to [a], while others are pronounced with $[æ]$, even by the same speaker. The remaining six vowels manifest clear phonemic contrasts illustrated below with minimal pairs. The vowel phonemes are summarized in Table 3. Corresponding symbols used in the orthography, if different from the IPA symbols, are included in angled brackets. The marginal three vowels are in parentheses. 


\begin{tabular}{|c|c|c|c|}
\hline $\mathrm{i}$ & $(\mathrm{y}<\ddot{\mathrm{u}}>)$ & $\dot{\mathrm{i}}<\ddot{\mathrm{e}}>$ & $\mathrm{u}$ \\
\hline $\mathrm{e}$ & $(\varnothing<\ddot{\mathrm{o}}>)$ & & $\mathrm{o}$ \\
\hline & $(\mathfrak{x}<\ddot{\mathrm{a}}>)$ & $\mathrm{a}$ & \\
\hline
\end{tabular}

Table 3: Chuxnabán Mixe vowel inventory

The following minimal pairs illustrate the phonemic contrasts.

\begin{tabular}{|c|c|c|c|c|c|}
\hline $\begin{array}{l}/ \mathrm{i} \sim ~ \ddot{\mathrm{e}} / \\
\underline{t s i p}\end{array}$ & ‘war' & $\begin{array}{l}/ \mathrm{a} \sim \mathrm{u} / \\
\text { kamp }\end{array}$ & 'field' & $\begin{array}{l}/ \mathrm{u} \sim \mathrm{i} / \\
\text { tsuk }\end{array}$ & 'mouse' \\
\hline$\underline{t s \ddot{e} p}$ & 'plant name' & $\underline{\text { kump }}$ & 'sweet fruit' & $\underline{t s i k}$ & 'coati' \\
\hline $\begin{array}{l}\text { lo } \sim u \sim \ddot{e} / \\
\text { joon }\end{array}$ & 'bird' & $\begin{array}{l}\text { le ol } \\
\text { wek }\end{array}$ & 'hook tool' & $\begin{array}{l}\text { le u/ } \\
\text { teky }\end{array}$ & 'foot' \\
\hline $\begin{array}{l}\text { juun } \\
\text { jëen }\end{array}$ & $\begin{array}{l}\text { 'hard' } \\
\text { 'fire' }\end{array}$ & $\underline{w o k}$ & 'gutter' & $\underline{t u k y}$ & 'to cut' \\
\hline $\begin{array}{l}l e \sim \ddot{e} / \\
m e j\end{array}$ & 'deep' & $\begin{array}{l}\text { la } \sim \ddot{e} / \\
\text { taajk }\end{array}$ & 'village police' & & \\
\hline$\underline{m \ddot{e} j}$ & 'large' & 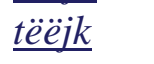 & 'house' & & \\
\hline$/ a \sim \ddot{a} /$ & & $/ a \sim \ddot{a} /$ & & & \\
\hline taak & 'mother' & maajtsk & 'the one who grabs' & & \\
\hline tääk & 'suddenly' & määjitsk & 'two' & & \\
\hline
\end{tabular}

The minimal pairs contrasting /a/ and /ä/ may result from interdialectal borrowing, given that Mixean varieties differ mostly in their vowel systems. Furthermore, there is speaker variation, in addition to token variation. The words with the fronted vowels are sometimes pronounced with [a] instead of [æ], and speakers will generally view both pronunciations as being the same word.

$\begin{array}{ll}\underline{\text { taapë/tääpë }} & \text { 'this one' } \\ \underline{\text { maajtsk/määjtsk }} & \text { 'two' } \\ \underline{\text { tsak/tsäk }} & \text { 'dull' }\end{array}$

Moreover, the fronted vowel [æ] is often found in palatalized environments, i.e. next to a palatal glide or affected by morpheme-induced palatalization.

\begin{tabular}{|c|c|}
\hline Palatalized environments: & $\frac{\frac{u n y \ddot{a} \ddot{a} p y}{i n \ddot{a}{ }^{\prime} \ddot{a} n y}}{\frac{y a ̈{ }^{\prime} \ddot{n}}{y}}$ \\
\hline
\end{tabular}

The other two marginal vowels, $[\varnothing]$ and $[\mathrm{Y}]$, most often occur in verbs and always in palatalized environments, as shown below. Given the lack of minimal pairs, these vowels are treated as marginal representing fronted allophones of $/ \mathrm{o} /$ and $/ \mathrm{u} /$ respectively. 


\begin{tabular}{|c|c|c|c|}
\hline yö’öpy & 'to walk' & pü̈̈ру & 'to wash' \\
\hline paayö'öpy & 'to find out, ask' & mёуü̈̈̈jy & 'get someone used to' \\
\hline michööpy & 'to count' & amaymüükypy & 'to count everything' \\
\hline tsaajpkäpnyöchy & 'reed' & tyü'üch & 'he hid them' \\
\hline 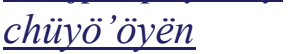 & 'the same' & jyüüka'të & 'they lived' \\
\hline
\end{tabular}

The effects of suprasegmental palatalization on $/ \mathrm{o} /$ and $/ \mathrm{u} /$ are illustrated below.

$\begin{array}{llll}\text { tsu'uch } & \text { 'meat' } & \text {-> chü'üch } & \text { 'his/her meat' } \\ \text { puuy } & \text { 'leg' } & ->\text { pyü̈̈y } & \text { 'his/her leg' } \\ \text { juuy } & \text { 'to buy' } & ->\text { jyüüy } & \text { 'he/she bought it' } \\ \text { jo'kp } & \text { 'to weave' } & ->\text { jyö'kypy } & \text { 'he/she weaved it' } \\ \text { noky } & \text { 'paper' } & ->\underline{n y o ̈ k y} & \text { 'his/her paper' }\end{array}$

In addition to the different vowel qualities, the complex vowel system shows a phonemic contrast between short and long vowels and between modal, breathy or aspirated, and glottalized or creaky vowels. A three-way vowel length distinction, as noted in other Mixean languages (Hoogshagen 1959; Van Haitsma 1976), does not occur in Chuxnabán Mixe (Jany 2007). Non-modal phonation contrasts depend on laryngeal timing. While breathiness occurs only in the last portion of the vowel, glottalization or creakiness can be found in the last, the middle, or the first portion of the vowel. These timing differences are related to differences in function. The first two involve a phonemic contrast between plain, glottalized, and interrupted vowels. The third occurs in vowel-initial words where a glottal stop is inserted initially to function as onset. Overall, the contrasts result in the following types of syllable nuclei: $\mathrm{V}, \mathrm{VV}, \mathrm{VV}^{\mathrm{h}}, \mathrm{V}^{\mathrm{T}}$, and $\mathrm{V}^{\mathrm{T}} \mathrm{V}$.

\subsection{Modal vowels}

There are nine vowel qualities [a, e, i, o, u, i, æ, $\emptyset, \mathrm{Y}]$ including three vowel qualities [æ, $\emptyset, \mathrm{Y}]$ that have most likely developed from suprasegmental palatalization causing the fronting of [a, $\mathrm{o}$, $\mathrm{u}$ ] in palatalized environments. To determine the vowel qualities, the first and the second formants for each vowel were measured in four speakers, two males and two females. Long vowels in stressed syllables in monosyllabic words were chosen for the measurements, except for $[\varnothing]$ and $[\mathrm{Y}]$ where not enough examples were available. The most steady portion of the vowel, generally the middle, was measured over a stretch of $20 \mathrm{~ms}$, as suggested in Ladefoged (2003). Two instances of five words per vowel were measured for each speaker. Praat was used to calculate the formants and Excel to develop the vowel plots with the first formant F1 on the vertical axis and the second formant F2 on the horizontal axis. Given that F1 inversely correlates with vowel height and F2 correlates with backness, the vowel plot roughly represents the vowel space. The results indicate that there is no overlap in vowel space between the different vowel qualities. Furthermore, [a] and [i] are central vowels and [æ], [ø], and [Y] are almost identical in terms of frontness. All four speakers show the same distribution of vowel qualities. The vowel plots for one female and for one male speaker are shown in Figures 20 and 21. The mean formant values are summarized in Figure 22. 


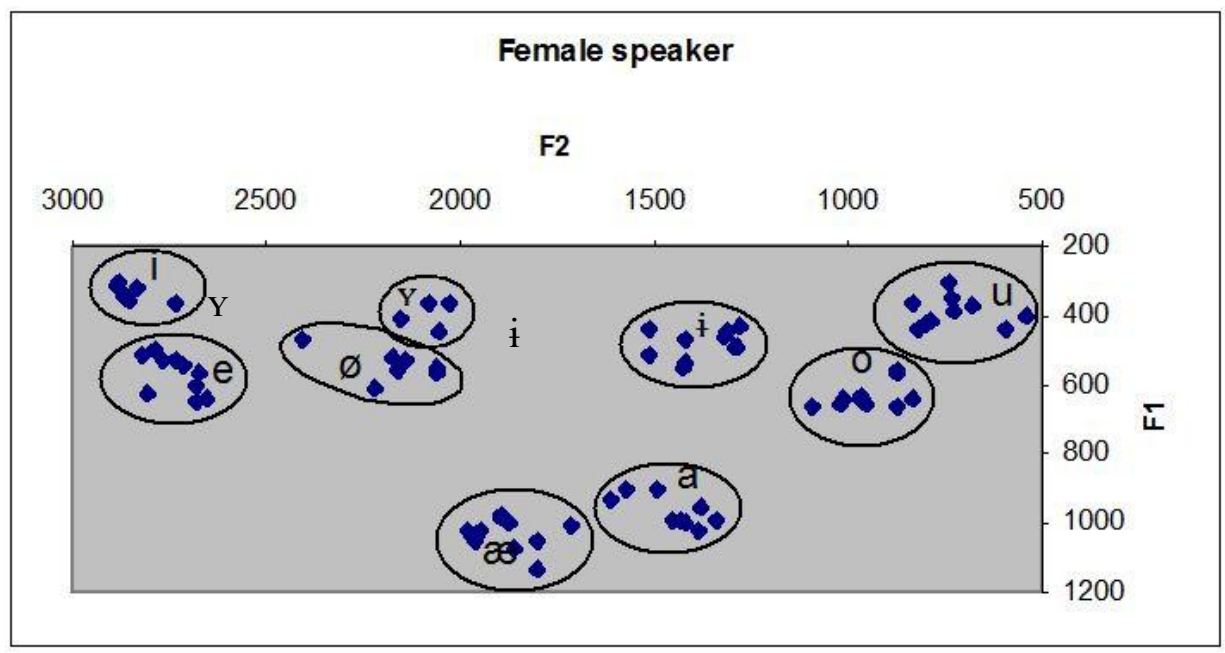

Figure 20: Vowel plot of female speaker

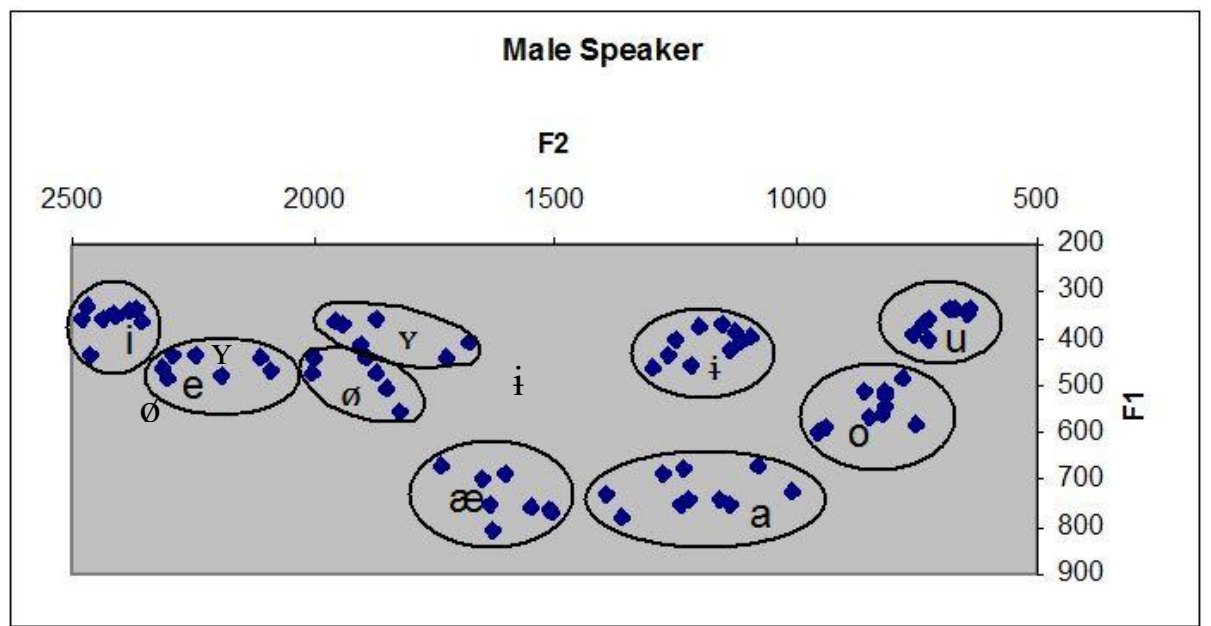

Figure 21: Vowel plot of male speaker

\begin{tabular}{|l|l|l|l|l|l|}
\hline \multicolumn{9}{|l|}{ Mean Formant Values in Hertz } \\
\hline Female & F1 & F2 & Male & F1 & F2 \\
\hline u & 389 & 725 & u & 360 & 697 \\
\hline o & 631 & 947 & o & 546 & 839 \\
\hline i & 482 & 1379 & i & 412 & 1185 \\
\hline a & 967 & 1451 & a & 726 & 1210 \\
\hline Y & 394 & 2078 & Y & 392 & 1845 \\
\hline$\varnothing$ & 546 & 2159 & $\varnothing$ & 481 & 1906 \\
\hline$æ$ & 1024 & 1864 & $\mathfrak{1}$ & 738 & 1602 \\
\hline i & 333 & 2843 & i & 349 & 2414 \\
\hline e & 569 & 2731 & e & 455 & 2250 \\
\hline
\end{tabular}

Figure 22: F1 and F2 mean values for one female and one male speaker

Figures 20-22 show that the vowel space is distributed identically for the male and the female speaker with higher formant frequencies for the female speaker as expected, given that women 
have a smaller vocal tract. For the male speaker, there is greater variation in F2 for [a] showing some instances closer [æ]. This can be explained with the occasional oscillation between the two vowels mentioned earlier.

Dieterman (2008) shows for the related Isthmus Mixe that vowels affected by secondary palatalization, the likely historic source for $[æ, \varnothing, Y]$ in Chuxnabán Mixe, do not impinge upon other phonemic vowel spaces. Similarly, in Chuxnabán Mixe [æ, $\varnothing$, y] do not penetrate the vowel space of other phonemic vowels, as shown in Figures 20 and 21. The three marginal vowels are only found in stressed syllables. Interestingly, Crawford (1984) states that Totontepec Mixe has nine contrastive vowel qualities in stressed syllables and only six in unstressed syllables. Unlike in Totontepec Mixe, however, in Chuxnabán Mixe the phonemic contrasts are not reduced; the three vowels simply do not occur in unstressed syllables.

Allophonic variations for all vowels include fronted allophones adjacent to palatalized consonants and /y/. The same has been reported by Dieterman (2008) for Isthmus Mixe. Ruiz de Bravo Ahuja (1980) and Crawford (1984) mention backed vowel allophones before velar consonants in Tlahuitoltepec Mixe and Totontepec Mixe respectively. The results for Chuxnabán Mixe are not conclusive in this regard.

The central high vowel $[\dot{i}]$ is devoiced word-finally, but only in certain words. The devoicing is not caused by a phonological process, but rather it is inherent to a nominalizing morpheme, as voiced and devoiced variants occur in the same environment. This is shown below and in Figures 23 and 24.

\begin{tabular}{|c|c|c|c|}
\hline \multirow[t]{5}{*}{ Voiceless [i] word-finally: } & $\underline{x u ' k p \ddot{e}}$ & 'to smell' & '['su'kpìt] \\
\hline & $\underline{t s o ' k p \ddot{e}}$ & 'to heal' & {$\left[{ }^{\mathrm{t}} \mathrm{tso}^{2} \mathrm{kp \grave {t }}\right]$} \\
\hline & $\underline{\text { poojkpë }}$ & 'to $\sin '$ & ['po: $\left.{ }^{\mathrm{h}} \mathrm{kpìo}\right]$ \\
\hline & jëëno’kpë & 'to have a fever' & [hì:n'o $\left.{ }^{2} \mathrm{kpij}\right]$ \\
\hline & pёёjkpë & 'pain’ & {$\left[\mathrm{pi:}^{\mathrm{h}} \mathrm{kp} \mathrm{kp}\right]$} \\
\hline \multirow[t]{4}{*}{ Voiced [i] word-finally: } & $\underline{\text { maa'tspë }}$ & 'thief' & ['ma: ${ }^{2}$ tspì $]$ \\
\hline & yaa'o'kpë & ‘murderer' & {$\left[j a:^{19} \mathrm{o}^{2} \mathrm{kpi}\right]$} \\
\hline & $\underline{\text { tsaajtspë }}$ & ‘carpenter’ & ['tsa: ${ }^{\mathrm{h}}$ tspì] \\
\hline & $\underline{o ’ k p \ddot{e}}$ & 'cadaver’ & ['o $\left.{ }^{2} \mathrm{kpi}\right]$ \\
\hline
\end{tabular}




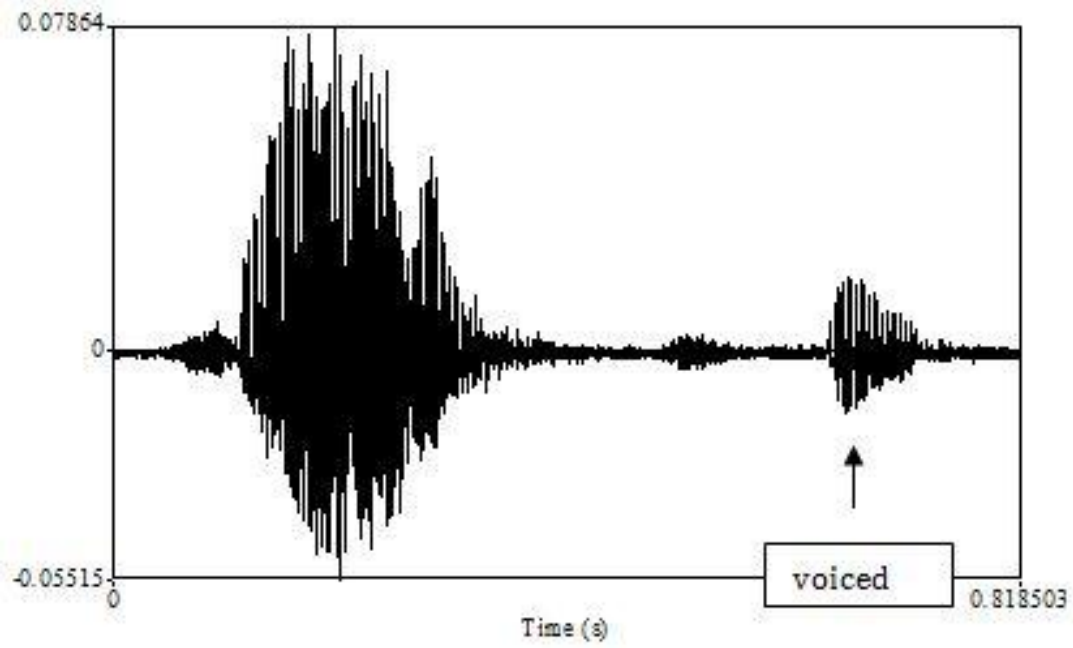

Figure 23: Waveform with voiced [i] in tsaajtspë 'carpenter'
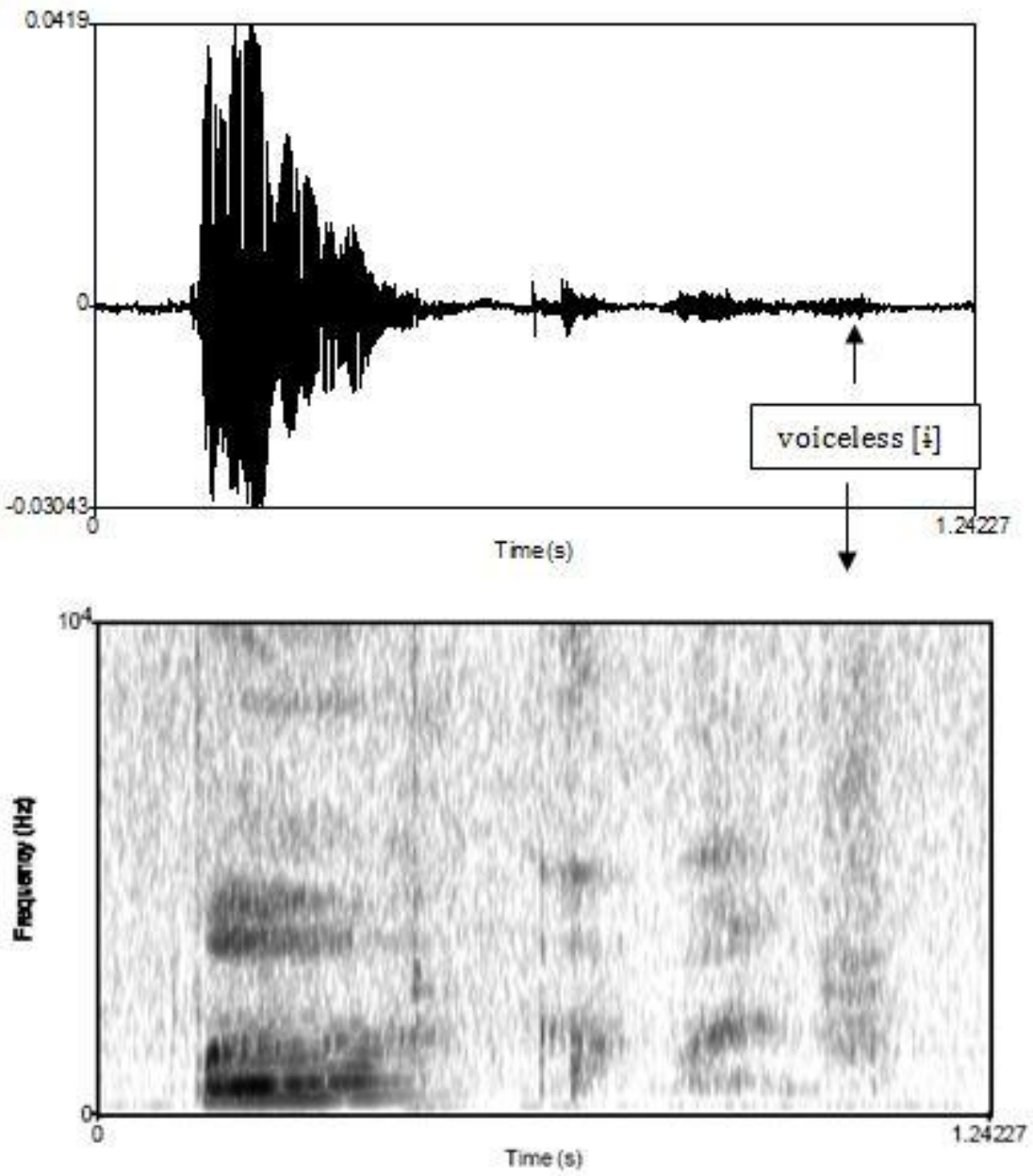

Figure 24: Waveform and spectrogram with voiceless [i] in pëëjkpë 'pain' 


\subsection{Breathy vowels}

Breathy or aspirated vowels occur with all vowel qualities and are phonemic, as shown below.

\begin{tabular}{|c|c|c|c|c|c|}
\hline & \multicolumn{2}{|l|}{$/ \mathrm{a} \sim \mathrm{aa}^{\mathrm{h} /}$} & \multicolumn{2}{|l|}{ /ëë ёё ${ }^{\mathrm{h}} /$} \\
\hline & 'mother' & pak & 'pigeon' & mëёt & 'they went \\
\hline taajk & 'police' & paajk & 'bone' & mëёit & 'year' \\
\hline /ë ëë & & $/ \mathrm{oO} \sim \mathrm{oo}^{\mathrm{h}} /$ & & $/ \mathrm{i} \sim \mathrm{iih}^{\mathrm{h}} /$ & \\
\hline mëk & 'strong' & poop & ‘white’ & pik & 'round' \\
\hline xё̈̈jk & ‘bean’’ & poojkp & 'to blow' & piijk & ‘ball’ \\
\hline$/ \mathrm{u} \sim \mathrm{uu}^{\mathrm{h}} /$ & & /ee $\sim \mathrm{ee}^{\mathrm{h}} /$ & & & \\
\hline$y u k$ & 'cold' & teech & 'father' & & \\
\hline уиијk & 'animal' & tseejch & 'type of plant' & & \\
\hline
\end{tabular}

Phonetically, breathy or aspirated vowels are characterized by a decay in intensity, especially during the second half of the vowel, and by post-vocalic aspiration, as can be observed by comparing Figures 25 and 26. Similar characteristics have been described for the so-called ballistic syllables: (a) a fortis release of the onset consonant, (b) a gradual surge and rapid decay in intensity, and (c) post-vocalic aspiration (Silverman 1997). However, Chuxnabán Mixe aspirated vowels show no gradual surge in energy, but rather a gradual decay throughout, as in Figure 26. Unlike in Jalapa Mazatec where non-modal phonation is most prominent in the first portion of the vowel (Silverman et al. 1995; Silverman 1997), aspiration in Chuxnabán Mixe is confined to the last part of the vowel. Contrary to Mixean languages, though, Jalapa Mazatec has contrastive tone. It has been argued (Silverman 1997) that non-modal phonation in Jalapa Mazatec is realized in the first portion of the vowel for tonal contrasts to be retrieved from the second portion.

When $/ \mathrm{h} /$ functions as an onset or a coda, its phonetic realization is different from the aspirated vowels. The turbulence in airflow is clearly stronger, and it is also longer in duration. Furthermore, in syllables where $/ \mathrm{h} /$ functions as a coda, the preceding vowel does not exhibit a steady decay in intensity as in aspirated nuclei (see Figures 12, 13, 25, and 26).

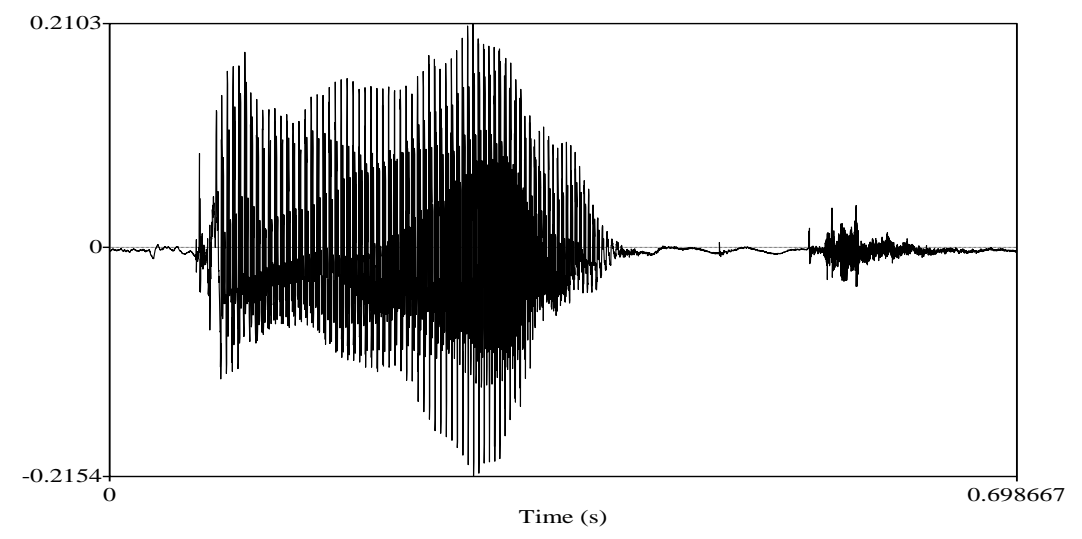




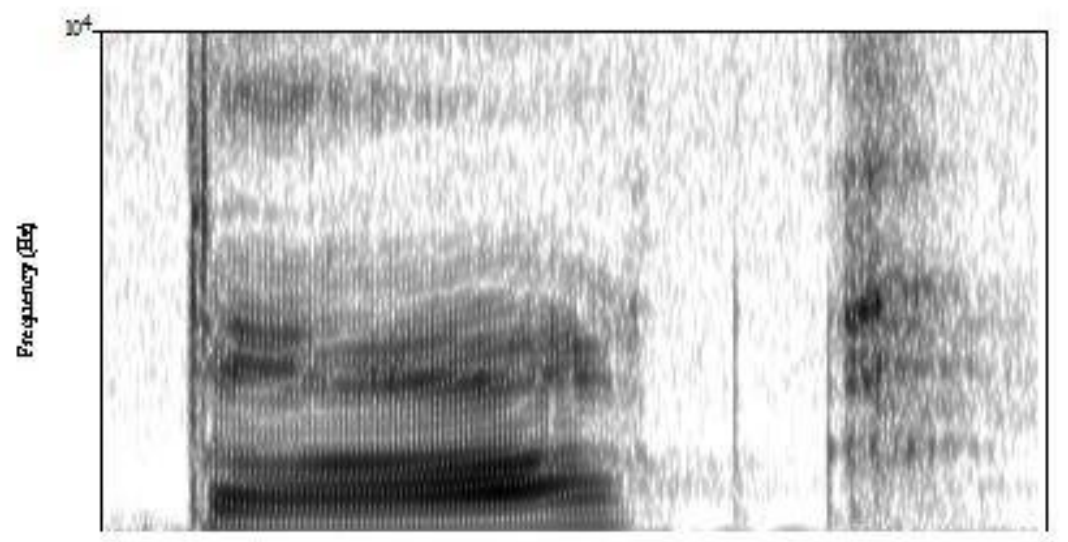

Figure 25: Waveform and spectrogram of plain long vowel in taak 'mother'
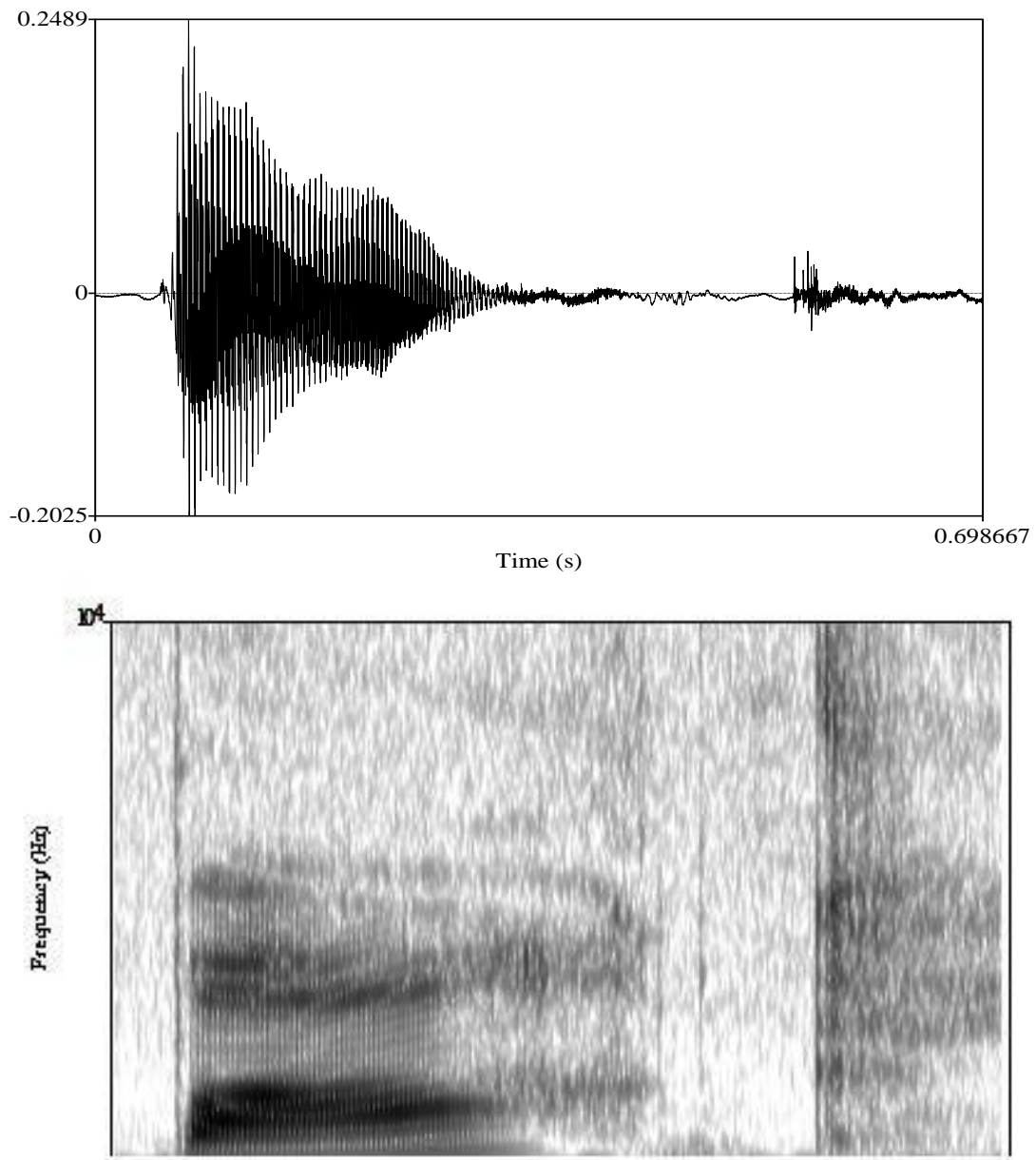

Figure 26: Waveform and spectrogram of aspirated long vowel in paajk 'bone'

Dieterman (2008) observes the same characteristics for aspirated vowels in Isthmus Mixe. They show a progressive loss of amplitude from the modal portion of the vowel with a weakening of the formant structures in the breathy portion of the vowel. Crawford (1963) and Ruiz de Bravo Ahuja (1980) describe a phonemic distinction between short breathy and long breathy vowels in 
Totontepec Mixe and Tlahuitoltepec Mixe respectively, while Van Haitsma (1976) and Dieterman (2008) report that there is no such contrast in San Juan El Paraíso Mixe and Isthmus Mixe respectively. In Chuxnabán Mixe there is no evidence for an additional phonemic length distinction in breathy vowels, the same as in the latter two languages.

\subsection{Creaky vowels}

Creakiness can occur in any portion of the vowel, i.e. at the beginning, in the middle, or at the end of the vowel, with a different function linked to each laryngeal timing. The latter two possibilities represent glottalized and interrupted vowels, each showing a phonemic contrast, as illustrated below. In glottalized vowels $\mathrm{V}^{2}$, the glottal stop forms part of the syllable nucleus, and it is realized phonetically as creakiness during the last portion of the vowel. This can be observed by comparing Figures 27 and 28. The creakiness correlates with a decay in intensity. Interrupted vowels $\mathrm{V}^{2} \mathrm{~V}$, as in Figure 30, are characterized by creakiness, as well as a decay in intensity, during the middle portion of the vowel, followed by a re-articulation of the vowel.

\begin{tabular}{|c|c|c|c|c|c|}
\hline$/ a \sim a^{2} /$ & & $/ u \sim u^{?}$ & & $/ \ddot{e} \sim \ddot{e}^{2}$ & \\
\hline täp & 'you have' & $\underline{t s u k}$ & 'mouse' & $\underline{m e ̈ k}$ & 'strong' \\
\hline$\underline{k a} p$ & 'scorpion' & ju’k & 'owl' & $\underline{m e} t$ & 'mother-in-law' \\
\hline$/ i i \sim i \stackrel{z}{l}$ & & $/ u u \sim u^{2} u /$ & & $\mid \ddot{e} \sim \ddot{e} \ddot{e} /$ & \\
\hline$\underline{k i i x}$ & 'woman' & puuy & 'seat & $\underline{t s \ddot{e} p}$ & 'plant name' \\
\hline pi'ix & 'tail' & pu'uy & 'table' & $\underline{t s \ddot{e} \prime \ddot{p} p}$ & 'plant getting cut' \\
\hline$/ u^{2} \sim u^{2} u /$ & & $\mid a a j \sim a^{2} a /$ & & $l e e \sim e^{2} e l$ & \\
\hline$p u^{\prime} t_{s}$ & 'yellow' & paajk & 'bone' & keepy & 'type of fish' \\
\hline pu'uts & 'infection' & $p a^{\prime} a k$ & 'sweet', & ke'eky & 'he went/left' \\
\hline
\end{tabular}

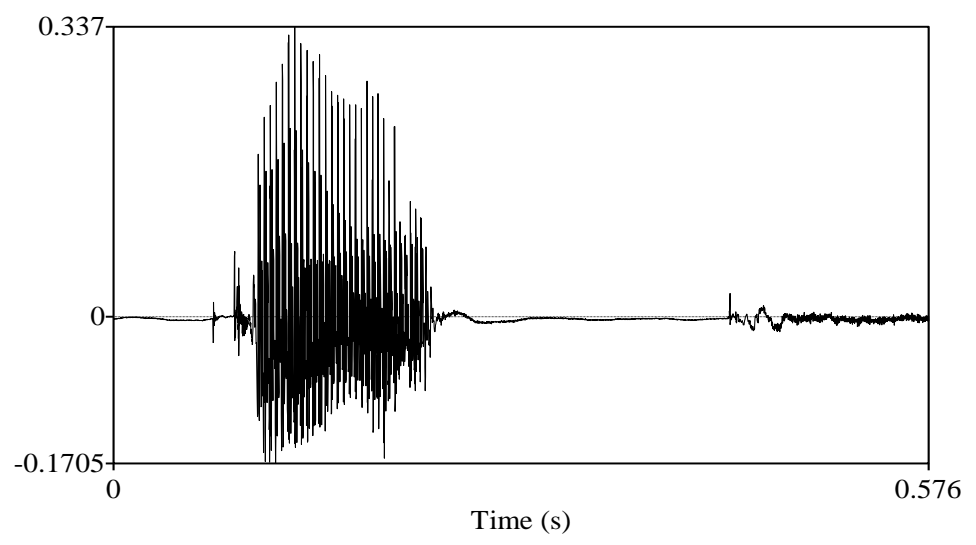




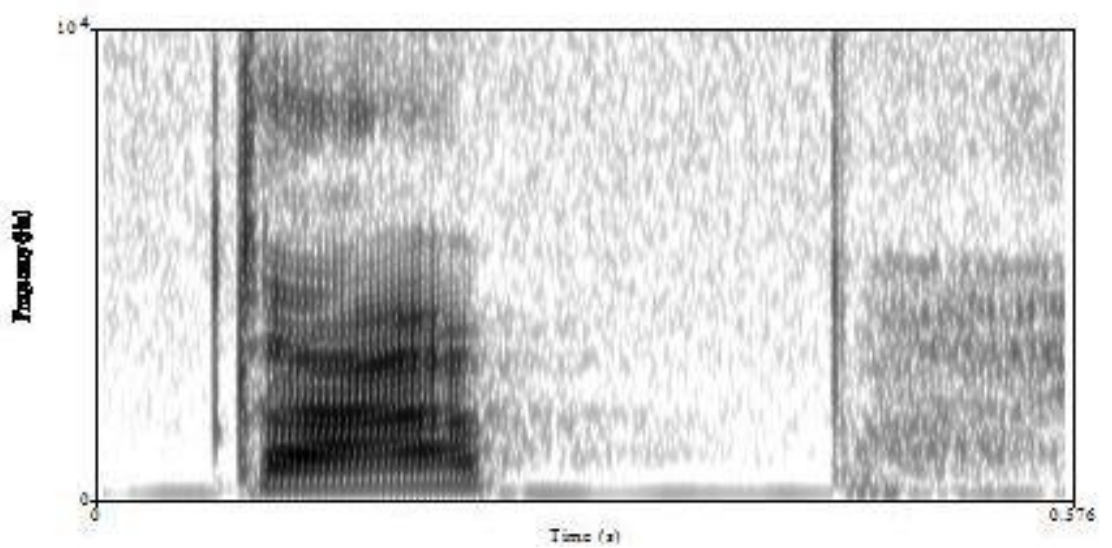

Figure 27: Modal short vowel in täp 'you have'
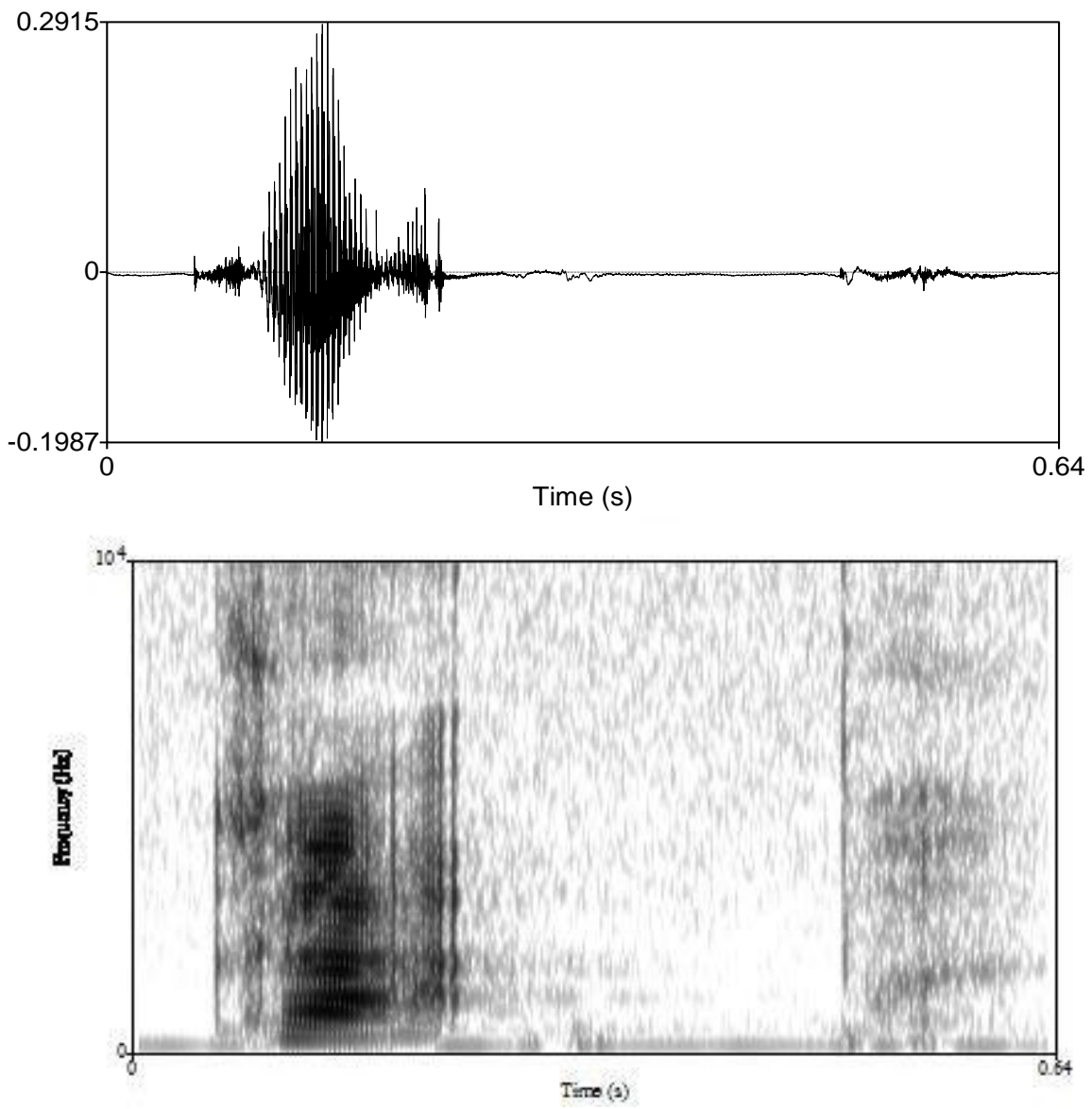

Figure 28: Glottalized vowel $V^{2}$ in $k \ddot{a}{ }^{p} p$ 'scorpion' 


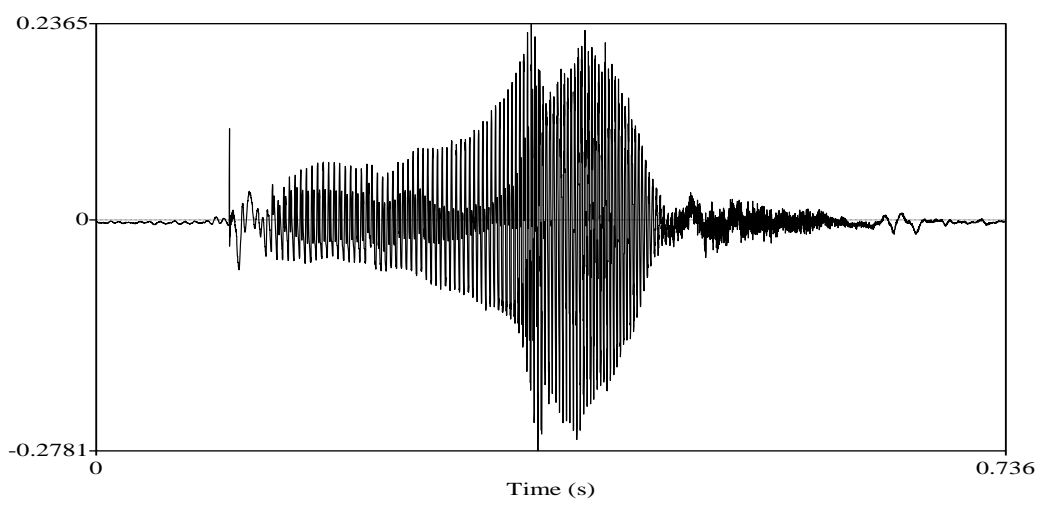

Figure 29: Modal long vowel in puuy 'seat'

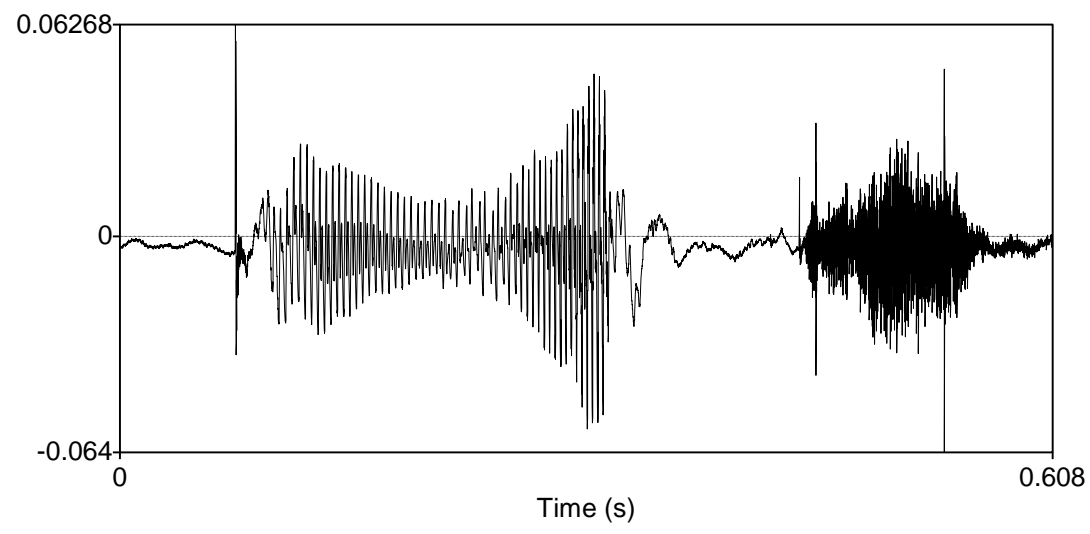

Figure 30: Interrupted vowel $\mathrm{V}^{2} \mathrm{~V}$ in pu'uts 'infection'

Glottalized and interrupted vowels have also been reported for Copala Trique, a Mixtecan language. Interestingly, Copala Trique also exhibits interrupted vowels of the form $\mathrm{V}^{\mathrm{h}} \mathrm{V}$ (Silverman 1997:236), not found in Chuxnabán Mixe.

Creakiness during the initial portion of the vowel results from the insertion of a glottal stop at the beginning of a vowel-initial word to function as an obligatory onset. The glottal stop is phonetically realized as creakiness during the first portion of the vowel, as in Figure 31. Glottal stops in coda position have not been found. Therefore, a contrast between a vowel-final glottal stop that forms part of the nucleus and one that represents a coda has not been observed, such as for the aspirated vowels where coda $/ \mathrm{h} /$ is different from nucleus $/ \mathrm{h} /$. 

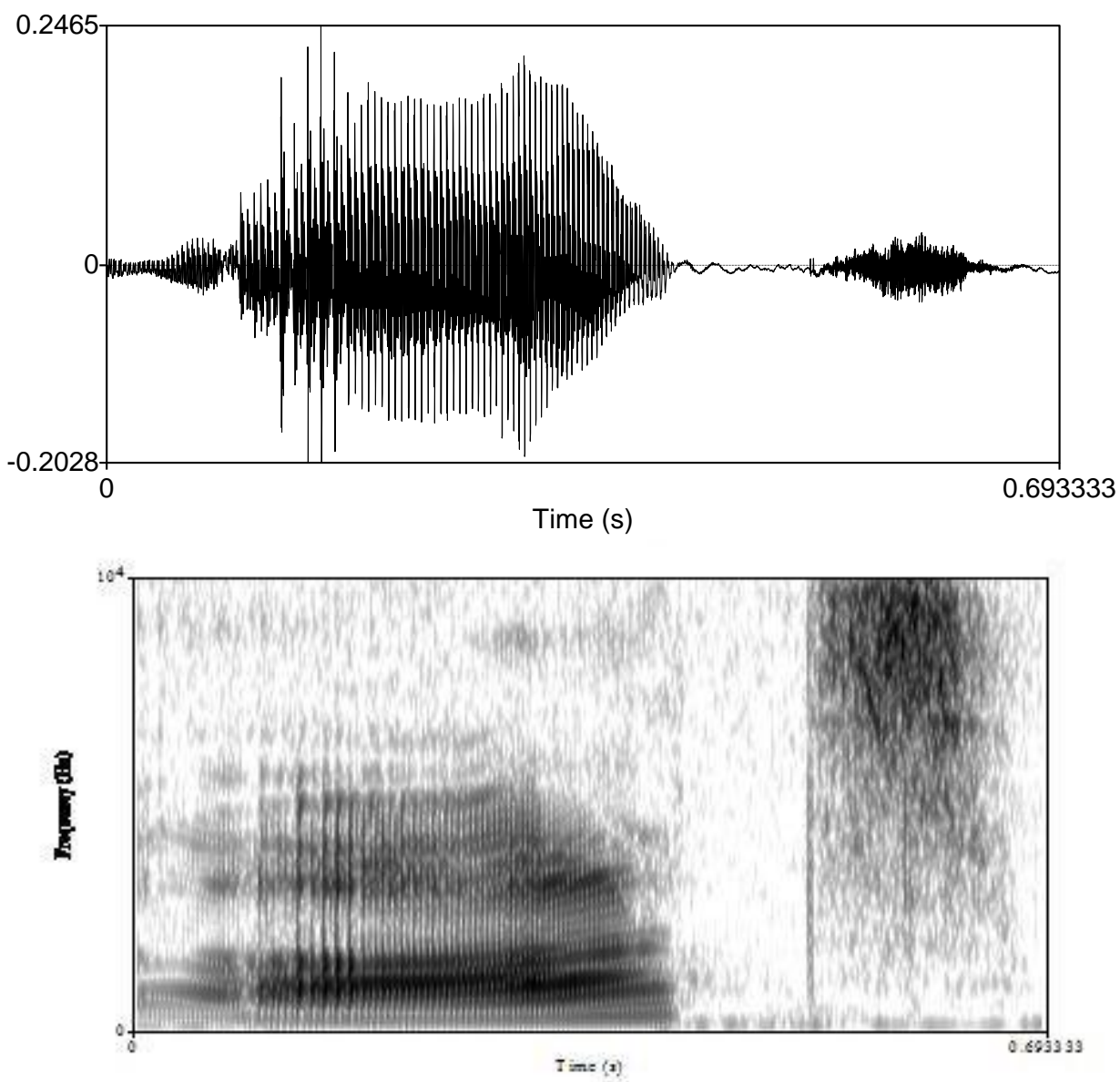

Figure 31: Insertion of initial glottal stop as creakiness in aats 'liana'

\subsection{Vowel length}

Chuxnabán Mixe, the same as all Mixean languages, shows a phonemic vowel length distinction between short and long vowels. This is also represented in the orthography.

\begin{tabular}{|c|c|c|c|c|c|}
\hline $\begin{array}{l}/ \mathrm{o} \sim \mathrm{oo} / \\
\frac{\operatorname{mox}}{\operatorname{moox}}\end{array}$ & $\begin{array}{l}\text { 'stomach' } \\
\text { 'knot' }\end{array}$ & $\begin{array}{l}\text { /i ii/ } \\
\text { tsik } \\
\text { tsiip }\end{array}$ & $\begin{array}{l}\text { 'coati raccon' } \\
\text { 'to bathe' }\end{array}$ & $\begin{array}{l}\text { le ee/ } \\
\text { kepy } \\
\text { keepy }\end{array}$ & $\begin{array}{l}\text { 'tree' } \\
\text { 'bream' }\end{array}$ \\
\hline /a aa/ & & /ë ëë/ & & $/ \mathrm{u} \sim \mathrm{uu} /$ & \\
\hline$\frac{\text { taak }}{p a k}$ & 'mother' & 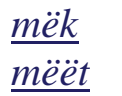 & $\begin{array}{l}\text { 'strong' } \\
\text { 'they went' }\end{array}$ & & $\begin{array}{l}\text { 'type of fruit' } \\
\text { 'iron' }\end{array}$ \\
\hline
\end{tabular}

A three-way phonemic vowel length contrast has been reported for Coatlán Mixe and San José El Paraíso Mixe (Hoogshagen 1959; Van Haitsma 1976). Hoogshagen (1959) examined possible influencing factors on vowel length in Coatlán Mixe and concluded that the three-way contrast does not depend on syllable structure, vowel quality, preceding or following consonants, or intonation. Nevertheless, according to Hoogshagen (1997), the three-way contrast is hard to hear for speakers, and is, therefore, not represented in the orthography. Bickford (1985), quoting 
Nordell, states for Guichicovi Mixe that the three-way vowel length distinction is not contrastive but conditioned by a fortis/lenis contrast in the final consonant whereby half-long vowels always occur before fortis consonants and full-long vowels before lenis. Bickford (1985) and Wichmann (1995) note that the fortis/lenis contrast only occurs in syllable-final position.

Chuxnabán Mixe, as well as Isthmus Mixe, only manifest a two-way vowel length distinction. Moreover, there is no evidence for a fortis/lenis contrast in consonants (Jany 2006; Dieterman 2008). Jany (2006) shows for Chuxnabán Mixe that vowel lengthening is triggered by either the insertion of a glottal stop in vowel-initial words, the lack of a coda, or by having a fricative coda /x/. When comparing modal and non-modal phonation the duration measurements in Jany (2006) reveal that in general modal vowels are shorter than their non-modal counterparts, except for the interrupted vowels. Interrupted vowels are longer than short modal vowels, but shorter than long modal vowels (Jany 2006).

While a distinction between short and long vowels is very common among the world's languages, a three-way phonemic vowel length contrast is typologically rare (Ladefoged and Maddieson 1996). Three-way vowel length distinctions occur in some Mixean languages, Yavapai (Tomas and Shaterian 1990), and Estonian (Lehiste 1970). In Estonian, however, the third degree of vowel length is dependent on syllable structure and word patterning (Lehiste 1970).

\section{Orthography}

The orthography for Chuxnabán Mixe was established in 2008 in collaboration with community members. It is the result of three design stages. When I started documenting the language in 2006, I worked for several months with a female speaker, who was living in the United States, prior to my first visit to the community. At that time, my written representation of Chuxnabán Mixe was purely phonetic using IPA symbols, in order to begin documenting the language and to examine the sound system. Once I defined the phonemes, I developed a tentative phonemic orthography. This served to prepare discussion points for a community-approved orthography to be elaborated during my second visit to the village. Village officials decided that orthography design should occur in consultation with younger speakers with a high school diploma, because the younger generation would benefit the most from having written records of their language, culture, and history. The current orthography was designed in collaboration with young community members during my field trip in 2008. My role was to provide guidance with linguistic issues and spelling options. All decisions were made by community members. The orthography was then informally tested with other young community members and approved. In the design process some changes were made to my previously elaborated tentative orthography. They include: (a) the use of voiceless stops $\langle\mathrm{p}, \mathrm{t}, \mathrm{k}\rangle$ for the voiced allophones [b, d, g] respectively, (b) the use of the symbol $\langle\ddot{e}\rangle$ instead of $\langle i \vec{i}\rangle$ for the high central vowel, and (c) with regard to suprasegmental palatalization, only the offglide after a palatalized consonant is written, but not the onglide preceding it, as in noky [nojk $\left.\mathrm{k}^{\mathrm{j}}\right]$.

In general, the following factors were considered when developing the orthography: (1) orthographies used for other Mixean languages and the general orthography established by the Mexican National Institute for Adult Education (INEA) for all Mixean languages, (2) Spanish orthography, given that community members are literate in Spanish, (3) having the simplest representation possible and, thus, using symbols found on basic keyboards rather than special IPA characters, and (4) only representing phonemes rather than allophones. With these four 
design principles in mind the following decisions were made by the community: (i) only phonemes are represented, i.e. voiced obstruents, such as [b, d, g, dz, d3], are not represented, except in Spanish loans, (ii) the vowels are represented in the same way as introduced by INEA using dieresis for special vowel qualities, as in ä, ë, ö, ü, rather than IPA symbols, (iii) Spanish orthography serves as the basis for the palatalized affricate, represented as <ch〉, and for the glottal fricative, written as $\langle\mathrm{j}\rangle$, (iv) Spanish loans are represented in their original orthography, (v) suprasegmental palatalization is written with a palatal glide $\langle y\rangle$ following the palatalized consonant, (vi) long vowels are represented by two consecutive vowels, and (vii) the glottal stop is written as an apostrophe. Some of the decisions made during this early stage may need to be revised after the documentation process has progressed and after extensive testing is conducted. Overall, the current orthography is very similar to those of other Mixean languages.

\section{Conclusions}

This paper represents the first comprehensive acoustic study of Chuxnabán Mixe, including a survey of the main consonant and vowel features. While Chuxnabán Mixe shows many areally and typologically common features, such as obstruent voicing in voiced environments, VOT patterns related to closure duration and place of articulation, nasal place assimilation, and consonant cluster reduction, among others, it also manifests typologically less common features, such as phonemic glottalization and aspiration of vowels and two distinct types of palatalization. Laryngeal timing of creakiness in vowels relates to differences in phonological function, i.e. distinctions between glottalized vowels and interrupted vowels and the insertion of a glottal stop in vowel-initial words. Moreover, the different acoustic realizations of the glottal fricative, equally linked to distinct phonological functions, i.e. an onset, a coda, or part of a phonemic vowel nucleus, illustrate the close relationship between phonetics and phonology and the importance of acoustic analysis for a better understanding of phonology. Another typologically interesting feature is palatalization, a suprasegmental phenomenon having distinct patterns when phoneme-induced or when morpheme-induced. Phoneme-induced palatalization does not affect a preceding segment, while morpheme-induced palatalization carries over to a segment to the left and to the right and affects entire consonant clusters. Palatalization also has an impact on the vowel system, possibly resulting in the emergence of new vowel phonemes in the language.

Whereas many of the same or similar features described here have also been reported for other Mixean and Mesoamerican languages, very few studies include acoustic evidence. Each Mixean community speaks a different variety of Mixe, some of which are mutually unintelligible. In many cases it is unclear whether a particular variety represents a distinct language or dialect, due to the limited documentation of Mixean languages. This work helps to shed some light on these relationships as it points out phonetic and phonological differences and similarities among Mixean languages. It also advances areal studies by showing how the Chuxnabán Mixe sound system fits into the Mesoamerican language area.

To conclude, although this study is primarily descriptive, it contributes to linguistic theory by showing how acoustic evidence can lead to a better understanding of phonology. Furthermore, the presence of irregular patterns indicating a sound change in progress, as observed with the assimilatory processes, and token and speaker variation of several acoustic features, such as the aspiration and release of stops, VOT, and nasal duration, demonstrate that languages are dynamic systems. Most importantly, however, this work aims at introducing the phonetics and phonology 
of a previously undescribed language, thus adding to the knowledge of Mixean and other Mesoamerican languages in general.

\section{References}

Bickford, Albert J. 1984. Vowel Shifts in Mixe. Linguistic Notes from La Jolla. 18-48.

-----. 1985. Fortis/lenis consonants in Guichicovi Mixe: a preliminary acoustic study. Work Papers of the Summer Institute of Linguistics, University of North Dakota 29: 195-207.

Blankenship, Barbara. 1997. The time course of breathiness and laryngealization in vowels.

Dissertation, UCLA. Source: www.linguistics.ucla.edu/faciliti/research/blankenship.pdf

-----. 2002. The timing of nonmodal phonation vowels. Journal of Phonetics 30. 163-191.

Brenzinger, Matthias, et al. 2003. Language Vitality And Endangerment. Paris: UNESCO Intangible Cultural Unit, Safeguarding Endangered Languages.

http://www.unesco.org/culture/ich/doc/src/00120-en.pdf. Last accessed July, 1, 2010.

Campbell, Lyle, Terrence Kaufman, Thomas C. Smith-Stark. 1986. Meso-America as Linguistic Area. Language, Vol. 62, No. 3. 530-570.

Campbell, Lyle. 1997. American Indian Languages: the historical linguistics of Native America. New York: Oxford University Press. 344-346.

Crawford, John Chapman. 1963. Totontepec Mixe Phonotagmemics. Summer Institute of Linguistics, No. 8. University of Oklahoma.

Dieterman, Julia. 2008. Secondary palatalization in Isthmus Mixe: a phonetic and phonological account. Summer Institute of Linguistics, Dallas, Texas.

Dilley L., S. Shattuck-Hufnagel, and M. Ostendorf. 1996. Glottalization of word-initial vowels as a function of prosodic structure. Journal of Phonetics 24.423-444.

Gerfen, Chip, and Kirk Baker. 2005. The production and perception of laryngealized vowels in Coatzospan Mixtec. Journal of Phonetics 33. 311-334.

Grenoble, Lenore, and Lindsay Whaley. 2006. Saving languages: An introduction to language revitalization. Cambridge: Cambridge University Press.

Gordon, Matthew and Peter Ladefoged. 2001. Phonation Types: A Cross-linguistic Overview. Journal of Phonetics 29, 383-406.

Gordon, Matthew. 1998. The Phonetics and Phonology of Non-Modal Vowels: A CrossLinguistic Perspective. Berkeley Linguistics Society 24, 93-105.

Gordon, Raymond G., Jr. (ed.). 2005. Ethnologue: Languages of the World. $15^{\text {th }}$ Edition. Dallas, Texas: SIL International. http://www.ethnologue.com/. Last accessed July 1, 2010.

Hayes, Bruce. 1989. Compensatory lengthening in moraic phonology. Linguistic Inquiry 20. 253-306.

Hoogshagen, Searle. 1959. Three contrastive vowel lengths in Mixe. Zeitschrift für Phonetik und allgemeine Sprachwissenschaft 12: 111-15.

Hoogshagen Noordsy, Searle And Hilda Halloran Hoogshagen. 1997. Diccionario Mixe de Coatlán Oaxaca. Summer Institute of Linguistics. $2^{\text {nd }}$ edition $\left(1^{\text {st }}\right.$ edition 1993). Mexico.

INEA (Instituto Nacional para la Educación del los Adultos). 1994. Ayuk Ja'jy Y'ayuujk. Libro del Adulto, Población Mixe (Parte Baja). http://www.cdi.gob.mx/index.php?option=com_docman\&task=doc_download\&gid=122\&Ite mid=200019.

----. 1997. Ayuk Ja’jy Y’ayuujk. Libro del Adulto, Población Mixe (Parte Alta). http://www.cdi.gob.mx/index.php?option=com_docman\&task=doc_download\&gid=121\&Ite 
$\underline{\operatorname{mid}=200019}$.

----. 1997. Instructivo del Alfabetizador. Población Mixe, Oaxaca. http://www.cdi.gob.mx/index.php?option=com_docman\&task=doc_download\&gid=124\&Ite $\underline{\text { mid}=200019}$.

Jany, Carmen. 2006. Vowel Length and Phonation Contrasts in Chuxnabán Mixe. Santa Barbara Papers in Linguistics 18: Proceedings from the $9^{\text {th }}$ Annual Workshop on Native American Languages. University of California, Santa Barbara.

-----. 2007. Phonemic versus phonetic correlates of vowel length in Chuxnabán Mixe. Berkeley Linguistic Society Proceedings 33S: Languages of Mexico and Central America. University of California, Berkeley.

-----. To appear. Assimilatory Processes in Chuxnabán Mixe. Proceedings from the $13^{\text {th }}$ Annual Workshop on Native American Languages. University of California, Santa Barbara.

Keating, Patricia. 1993. Phonetic representation of palatalization versus fronting. UCLA Working Papers in Phonetics 85. 6-21.

Ladefoged, Peter. 2003. Phonetic Data Analysis: An Introduction to Fieldwork and Instrumental Techniques. Blackwell, Malden, MA.

----. 1993. A Course in Phonetics. Harcourts Brace College Publishers: San Diego.

Ladefoged, Peter and Ian Maddieson. 1996. The Sounds of the World's Languages. Blackwell, Malden, MA.

Lehiste, Ilse. 1970. Suprasegmentals. MIT Press, Cambridge, MA.

Lyon, Shirley. 1967. Tlahuitoltepec Mixe Clause Structure. International Journal of American Linguistics 33:1. 25-45.

Maddieson, Ian, Heriberto Avelino and Loretta O'Connor. 2009. The Phonetic Structures of Oaxaca Chontal. International Journal of American Linguistics 75:1. 69-101.

Remijsen, Bert and Leoma Gilley. 2008. Why are three-level vowel length systems rare? Insights from Dinka (Luanyjang dialect). Journal of Phonetics 38. 318-344.

Rhodes, Richard A. 2004. Ongoing Sound Change in Sayula Popoluca. Draft paper from $42^{\text {nd }}$ CAIL, Boston, MA.

Ruiz De Bravo Ahuja, Gloria. 1980. Mixe Tlahuitoltepec, Oaxaca. Archivo de Lenguas Indígenas de México.

Schoenhals, Alvin and Louise C. 1982. Vocabulario Mixe de Totontepec. Summer Institute of Linguistics. $2^{\text {nd }}$ edition ( $1^{\text {st }}$ edition 1965). Hidalgo, Mexico.

Silvermann, Daniel. 1997. Laryngeal complexity in Otomanguean vowels. Phonology 14. 235261.Silvermann, Daniel, Barbara Blankenship, Paul Kirk, and Peter Ladefoged. 1995. Phonetic structures of Jalapa Mazatec. Anthropological Linguistics 37:1. 70-88.

Suslak, Dan. 2003. The Story of ö: Orthography and Cultural Politics in the Mixe Highlands. Pragmatics 13:4. 551-563.

Thomas, Kimberly D. and Alan Shaterian. 1990. Vowel length and Pitch in Yavapai. Papers from the 1990 Hokan-Penutian Languages Workshop. Margaret Langdon ed. Carbondale, IL. 144-5.

Van Haitsma, Julia Dieterman and Willard Van Haitsma. 1976. A Hierarchical Sketch of Mixe as spoken in San José El Paraíso. Summer Institute of Linguistics, No. 44. Mexico.

Wichmann, Søren. 1995. The Relationship among Mixe-Zoquean Languages of Mexico. University of Utah Press, Salt Lake City. 
Author's contact information:

Carmen Jany

California State University

Department of World Languages and Literatures

San Bernardino, CA 92407-2393

cjany@csusb.edu 